\title{
Moradores de tinieblas: la jurisprudencia del Tribunal Constitucional peruano ante el derecho a la igualdad de personas privadas de libertad en centros penitenciarios ${ }^{1}$
}

\author{
Dwellers of Darkness: Peruvian Constitutional Court Case Law on Right to \\ Equality of Persons Deprived of Liberty in Prisons
}

\begin{abstract}
Abraham SILES ${ }^{2}$
«MORADORES DE TINIEBLAS Y DE SOMBRA DE MUERTE, PRISIONEROS EN MISERIA Y EN CADENAS». SALMOS 107:10.
\end{abstract}

\begin{abstract}
Resumen: El artículo examina hasta qué punto la jurisprudencia del Tribunal Constitucional peruano protege los derechos fundamentales de las personas privadas de libertad en centros penitenciarios, en aplicación del derecho/principio de igualdad. Para ello se contrasta dos concepciones de igualdad: igualdad como no discriminación e igualdad como no sometimiento. Especial atención se concede a esta segunda visión, como idónea para el abordaje de la situación de grupos que sufren discriminación estructural o que se hallan en situación de especial vulnerabilidad, como se propone que ocurre con los reclusos. El artículo encuentra que la jurisprudencia del Tribunal Constitucional del Perú procura tutelar el igual disfrute y ejercicio de derechos fundamentales por los reclusos, mostrando evolución favorable a lo largo del tiempo. En particular, es interesante el uso del habeas corpus correctivo y, más recientemente, de la declaración de estado de cosas inconstitucional, en el caso de internos con discapacidad mental y en el caso del hacinamiento carcelario. Quedan, sin embargo, tareas pendientes, como mejorar el reconocimiento y participación de los reclusos como colectivo desaventajado.
\end{abstract}

Palabras clave: Derecho a la igualdad, no discriminación, presos, cárceles

\footnotetext{
${ }^{1}$ Artículo elaborado como parte de un proyecto de investigación sobre la jurisprudencia del Tribunal Constitucional y el derech o a la igualdad de grupos vulnerables en el Perú, apoyado por el Vicerrectorado de Investigación de la Pontificia Universidad Cat ólica del Perú (proyecto 570). Agradezco a mis compañeros del Grupo de Investigación en Derecho Constitucional y Derechos Fundamentales (GIDCYDEF) por sus comentarios a versiones preliminares del artículo, en especial, a César Landa, David Lovatón, Elena Alvites, Marco Rodríguez, Jorge León y Juan Carlos Díaz.

2 Profesor de Derecho Constitucional de la Pontificia Universidad Católica del Perú, coordinador del Grupo de Investigación en Derecho Constitucional y Derechos Fundamentales (GIDCYDEF). Código ORCID: 0000-0003-2959-6242. Correo electrónico: asiles@pucp.edu.pe.
} 


\begin{abstract}
The article examines the extent to which Peruvian Constitutional Court case law protects the fundamental rights of persons deprived of liberty in prisons, in application of the right / principle of equality. For this, two conceptions of equality are contrasted: equality as nondiscrimination and equality as non-subjugation. Special attention is paid to this second vision, as ideal for addressing the situation of groups that suffer structural discrimination or that are in a situation of special vulnerability, as is proposed to be the case with prison inmates. The article finds that Constitutional Court case law of Peru seeks to protect the equal enjoyment and exercise of fundamental rights by prison inmates, showing favorable evolution over time. In particular, the use of corrective habeas corpus and, more recently, of the declaration of unconstitutional state of affairs is interesting, in the case of prisoners with mental disabilities and in the case of prison overcrowding. However, pending tasks remain, such as improving the recognition and participation of prison inmates as a disadvantaged group.
\end{abstract}

Keywords: Right to equality, non-discrimination, prisoners, jails

\title{
1. Introducción
}

En el Perú, los estudios de Derecho Constitucional han descuidado la cuestión de los derechos fundamentales de las personas privadas de libertad en centros penitenciarios. El «constitucionalismo de los derechos» peruano, muy activo en diversas esferas, ha omitido reflexionar, de modo consistente y continuo, sobre la situación que atraviesan quienes padecen reclusión en las cárceles del país. Esta deserción académica, este abandono parecen especialmente significativos, ya que las múltiples deficiencias del sistema carcelario son de notoria gravedad y se arrastran desde mucho tiempo atrás.

En realidad, el problema es de naturaleza estructural, tiene raíces históricas y se refiere a un grupo social desaventajado o que se halla en condiciones de particular vulnerabilidad. La pregunta más radical es, desde luego, la que inquiere por los límites intrínsecos de un modelo penal sustentado en la cárcel como «institución total» a cargo del Estado, llamada a garantizar los derechos fundamentales de los reclusos — vida, integridad, salud, educación, trabajo, libertades comunicativas, participación en la vida nacional, entre otros-, con el propósito de conseguir su rehabilitación y reinserción social, pero que se muestra una y otra vez incapaz de hacerlo.

Se ha dicho, por ello, que la cárcel equivale a una «contradicción institucional», en la medida en que ha sido confiada al «control total del Estado», pese a lo cual a su interior no prevalecen controles ni reglas, sino «la ley del más fuerte»33. Se reproduce así el «Estado de naturaleza», que

${ }^{3}$ Ferrajoli (2016), p. 7. 
prescinde del Derecho, con lo que las cárceles, de manera paradójica, se configuran entonces como espacios en los que «a la máxima seguridad externa le acompaña la máxima inseguridad interna», signada por graves y constantes violaciones de los derechos fundamentales de los reclusos $^{4}$. Nada sorprendente, a decir verdad, pues ya el clásico estudio de Michel Foucault había advertido: «se saben todos los inconvenientes de la prisión, y que es peligrosa cuando no es inútil. Y, no obstante, no se "ve" por qué reemplazarla. Es la detestable solución que no se puede evitar» ${ }^{5}$

Pero, aun si no se admitiera cuestionamientos teóricos y prácticos tan extremos, es clara la multicausalidad de los males que agobian al sistema penitenciario en el Perú y sus conexiones con características básicas del orden político y social del país, un orden de grandes desigualdades y exclusiones ${ }^{6}$. En consecuencia, para su solución es necesario el trabajo concertado de un conjunto de autoridades públicas y aun de organizaciones de la sociedad civil, en la elaboración e implementación de políticas comprehensivas que remuevan condiciones de injusticia estructural y prolongada.

Por lo demás, la experiencia carcelaria es tan fuerte y devastadora que quienes la viven conforman un grupo social distinto y separado del resto de la comunidad nacional, adquiriendo ciertos rasgos identitarios como colectivo o minoría objeto de dominación, violencia y segregación ${ }^{7}$. Así, el encierro expiatorio de delincuentes condenados o presuntos acarreará una impronta indeleble incluso a aquellos que dejen la prisión, quienes difícilmente podrán desprenderse del estigma del descenso a los infiernos que supone la reclusión carcelaria en el Perú8.

Frente al desafío enorme de las prisiones y su efecto deshumanizador, la respuesta de la jurisdicción constitucional está llamada a ser especialmente significativa, en cuanto encargada de hacer valer la fuerza vinculante de la Constitución y otorgar tutela efectiva a los derechos fundamentales de todas las personas, en particular, de grupos que sufren violencia y discriminación estructural e histórica, como son los presos. De allí la relevancia de conocer y analizar la jurisprudencia del Tribunal Constitucional sobre los derechos de los reclusos y las condiciones de internamiento penitenciario, desde el prisma del principio/derecho de igualdad.

\footnotetext{
${ }^{4}$ Ferrajoli (2016), p. 7.

${ }^{5}$ Foucault (2019), p. 266.

${ }^{6}$ Pérez (1994), pp. 195, 197-198; CEAS (2015), pp. 9-11, 13-14.

${ }^{7}$ Gargarella (2008), pp. 36-37; Ariza (2011), pp. 21-22.

${ }^{8}$ CEAS (2015), pp. 19, 22, 31, 38.
} 
En lo que sigue se abordará primero las distintas nociones del principio de igualdad (2) y la presentación de la normativa primordial aplicable en el Perú a partir de la Constitución (3), para luego estudiar las sentencias más importantes que ha emitido el Tribunal Constitucional en materia del principio/derecho a la igualdad de personas privadas de libertad en centros penitenciarios; singular atención se concederá al desarrollo del hábeas corpus correctivo y, sobre todo, al empleo de la institución del «estado de cosas inconstitucional» (4). El texto se cierra con un acápite conclusivo (5).

\section{Dos concepciones del derecho/principio constitucional de igualdad}

Diversos estudios actuales de Derecho Constitucional y DIDH muestran que la concepción tradicional de la igualdad como «no discriminación» resulta insuficiente para enfrentar situaciones estructurales que afectan a determinados grupos desaventajados. Surge, en consecuencia, una concepción distinta, de igualdad como «no sometimiento» o «no subordinación», que atiende a los elementos históricos y fácticos que determinan que tales grupos se vean en la imposibilidad real de superar las barreras que les impiden el pleno e igual disfrute de sus derechos fundamentales ${ }^{9}$.

\subsection{IGUALDAD COMO NO DISCRIMINACIÓN}

La concepción de la igualdad como no discriminación tiene como idea central la proscripción de todas las distinciones arbitrarias o irrazonables ${ }^{10}$. Su primera manifestación histórica suponía que las personas deben ser tratadas de la misma manera, en la medida en que se encuentren en condiciones semejantes. Ni la ley ni su aplicación, por lo tanto, podían hacer diferencias, sino que, más bien, debían aspirar a una neutralidad e impersonalidad que desterrara todo privilegio.

Así, la igualdad era entendida principalmente como una igualdad jurídica y formal, de dimensión individual, en cuya virtud el legislador había de procurar el mismo trato a quienes estuvieran en igualdad de condiciones ${ }^{11}$. De aquí se derivaba que los órganos competentes

${ }_{9}^{9}$ Fiss (1999), pp. 144-145; Saba (2018), pp. 30-32; Añón (2013), pp. 136-137, 147-151; Díaz de Valdés (2015), pp. 173-176; Salomé (2017), pp. 280-285.

${ }^{10}$ Saba (2018), pp. 38, 40, 50; Clérico et al. (2013), p. 118; Ronconi (2019), p. 108.

${ }^{11}$ Ronconi (2019), p. 106; Eguiguren (2002), p. 97; Salomé (2015), p. 23. 
debían limitarse a hacer aplicación de la ley de manera imparcial a todos los sujetos comprendidos en su supuesto habilitante ${ }^{12}$.

La primera Constitución del Perú, la Carta liberal de 1823, recogió también ese ideal igualitario13. Así, al consagrar la República (Preámbulo) y el gobierno «popular representativo» (art. 27), con división de poderes entre Legislativo, Ejecutivo y Judiciario (art. 28), estableció no sólo la independencia de la nación respecto de la «monarquía española» y de «toda dominación extranjera» (art. 2), sino que estipuló a la vez que «si la Nación no conserva o protege los derechos legítimos de todos los individuos que la componen, ataca el pacto social» (art. 4) (cursivas añadidas). A ello agregó la significativa prohibición de «decretar leyes que atenten a los derechos individuales» (art. 5) y la no menos relevante inviolabilidad de «la igualdad ante la ley, ya premie, ya castigue» (art. 193.9) ${ }^{14}$.

El problema con esta plasmación inicial de una mera igualdad jurídica formal —la cual atraviesa las décadas y llega hasta hoy, como una de las dimensiones del principio igualitario, necesaria aunque insuficiente- es que no toma en cuenta las razones de la clasificación que realiza el legislador, por lo que puede ocurrir que los criterios clasificatorios sean arbitrarios e injustificados ${ }^{15}$. En consecuencia, la ley podía distinguir siempre que tal distinción se basara en un criterio objetivo a aplicar con imparcialidad a todos los sujetos comprendidos en la norma.

Un ejemplo histórico extremo de esta concepción es el ofrecido por la célebre sentencia emitida por la Corte Suprema de Estados Unidos de América en el caso Plessy vs. Ferguson, de 18 de mayo de 1896. En efecto, en este caso, la Corte validó la doctrina «separados pero iguales» que permitía una diferenciación basada en criterios raciales, conforme a la cual los blancos y las personas de color tendrían regímenes legales distintos, a condición de que el trato dentro de cada grupo fuera idéntico ${ }^{16}$.

La reacción frente a las deficiencias de esta primera versión de la igualdad consistirá en superar su formalismo y distanciamiento de la realidad mediante una aproximación de naturaleza «material». Esta se interroga ahora por el contenido o materia de las clasificaciones

\footnotetext{
${ }^{12}$ Ronconi (2019), p. 106; Eguiguren (2002), p. 97; Salomé (2015), p. 25.

${ }^{13}$ Sobre el liberalismo de quienes integraron la primera asamblea constituyente del Perú y de la Carta que redactaron, véanse Porras Barrenechea (1974), p. 198; Basadre (1983), p. 4; Pareja Paz-Soldán (1984), p. 32; Alzamora (2004), p. 214-215; Villarán (1962), pp. 42-43.

${ }^{14}$ Los artículos de la Constitución de 1823 se citan de Ramos (2017), pp. 197-216.

${ }^{15}$ Saba (2018), pp. 39-40; Clérico y Aldao (2011), pp. 142, 145.

${ }^{16}$ Clérico et al. (2013), p. 118; Ronconi (2019), p. 106, nota 3; véase también, para un criterio similar en relación a la legislación nazi contra los judíos, Alexy (1997), p. 386.
} 
de la ley y además las refiere a la situación real de las personas y grupos sociales —a la dimensión fáctica, no a los meros enunciados legales-, en particular, con el propósito de promover la igualdad de oportunidades para todas las personas ${ }^{17}$.

Así, ya no se admitirá como válida cualquier diferenciación introducida por el legislador, sino que hará falta exhibir razones objetivas que la fundamenten y la doten de legitimidad constitucional ${ }^{18}$. A partir de entonces el legislador verá, pues, limitada su actividad por la propia Carta suprema bajo control de constitucionalidad a cargo de los jueces.

Expresión de este modelo de razonabilidad es, a nivel de la jurisprudencia de los tribunales, el test de razonabilidad o proporcionalidad que utilizan, desde la década de 1980 en adelante, el Tribunal Constitucional de Alemania y el de España, así como el Tribunal Europeo de Derechos Humanos (TEDH), y, posteriormente, la Corte IDH, la Corte Constitucional colombiana y el Tribunal Constitucional peruano, entre otros ${ }^{19}$. Se requerirá siempre la existencia de una causa objetiva y razonable, tal como lo reconoce el máximo tribunal regional en materia de derechos humanos ${ }^{20}$.

La evolución jurídica ha llevado a un juicio o modelo integrado de igualdad, que incorpora tanto los aportes del constitucionalismo europeo continental como el desarrollo en la materia debido a la jurisprudencia y doctrina constitucionales de Estados Unidos de América. El test «integrado» de igualdad, siempre con la finalidad de impedir tratos diferenciados arbitrarios o carentes de justificación objetiva y razonable, combina, de un lado, el juicio de proporcionalidad —que se despliega en los subprincipios de idoneidad, necesidad y proporcionalidad en sentido estricto-y, de otro lado, diversos grados de escrutinio jurisdiccional —a saber, leve, intermedio y estricto-, para apreciar las situaciones que pudieran configurar supuestos discriminatorios prohibidos por la Constitución y por los tratados internacionales de derechos humanos ${ }^{21}$.

Sin duda, la igualdad material, el juicio de proporcionalidad y los distintos grados de escrutinio de acuerdo con los supuestos a examinar -incluyendo su versión más elaborada, recogida en el modelo integrado de igualdad- son avances notables en el camino de la realización del ideal igualitario al que aspira el constitucionalismo desde sus orígenes, en armonía actualmente con el DIDH. Y tales avances han exigido largas décadas de confrontaciones

\footnotetext{
${ }^{17}$ Eguiguren (2002), p. 100; Nogueira (2006), pp. 67-68; Salomé (2015), pp. 25-27.

${ }^{18}$ Ronconi (2019), p. 108; Clérico y Aldao (2011), p. 145; Díaz de Valdés (2015), pp. 168-170.

${ }^{19}$ Ronconi (2019), p. 108, nota 5; Bernal (2005), p. 262; Landa (2018), pp. 33-37; Véase también Giménez (2004), pp. 57-69.

${ }^{20}$ Corte IDH (2003), párr. 89.

${ }^{21}$ Bernal (2005), pp. 274-279; Ronconi (2019), pp. 119-122; Clérico et al. (2013), p. 118.
} 
y luchas tanto en el terreno político-social como en el ámbito jurídico y académico, hasta alcanzar el alto nivel de sofisticación tutelar que se observa hoy en día.

No obstante, la concepción de la igualdad como no discriminación se resiente de una limitación esencial. Y es que la aparente neutralidad que declara, al proscribir tratos distintos que carecen de justificación, no es tal ante la situación concreta en que se hallan determinados colectivos sociales. La ley, pese a tener una intención noble y armoniosa con la Constitución, puede producir un impacto adverso sobre ciertas personas o grupos de la sociedad ${ }^{22}$. En estos casos, no es que el legislador procure discriminar; puede ser que persiga, más bien, el propósito de crear reglas igualitarias. No obstante, son las estructuras de la sociedad las que impiden la realización de dicha finalidad, provocando que la ley deje intactas o quizá agrave las condiciones de opresión o exclusión de los grupos desaventajados ${ }^{23}$.

La visión del principio de igualdad como no discriminación pone el acento en la dimensión individual del problema. Se plantea si es que determinada persona sufre un tratamiento diferenciado, sea en el texto de la ley o en su aplicación por los órganos administrativos o jurisdiccionales, que no cuenta con una causa objetiva y razonable que lo justifique. Pero no va más allá, dejando de lado, en consecuencia, el contexto social en el que el caso individual se inserta. No obstante, el problema discriminatorio puede presentarse inextricablemente unido a una situación de segregación o exclusión del disfrute de derechos básicos por un colectivo al que el individuo pertenezca. Es, pues, necesario trascender la dimensión individual o intersubjetiva, ya que, como sostiene María José Añón Roig, la desigualdad estructural «tiene una faceta o dimensión colectiva o grupal definitoria», de suerte que el «trato desigual e injusto» que las personas padecen individualmente se debe a que «comparten o se les atribuyen unas características, rasgos o prejuicios propios de una colectividad» 24 .

La visión de la igualdad como mera no discriminación, con su sesgo individualista, desapercibe dos variantes especialmente insidiosas de discriminación, a saber, la discriminación indirecta y la múltiple o interseccional. La primera, la modalidad discriminatoria indirecta, es la que se acaba de referir para contrastar la dimensión individual con la estructural del fenómeno discriminatorio. Es decir, hay discriminación indirecta en aquellos casos en que la ley contiene un tratamiento neutral en su formulación, pero cuya aplicación o puesta en práctica conduce a

\footnotetext{
${ }^{22}$ Ronconi (2019), p. 123.

${ }^{23}$ Ronconi (2019), p. 123; Courtis (2010), pp. 109-110; Nogueira (2006), p. 88.

${ }^{24}$ Añón (2013), p. 134.
} 
unos resultados desfavorables para ciertas personas o cierto grupo social, al afectarlos debido precisamente a la situación de desventaja estructural en la que se hallan²5.

De otro lado, quienes conciben la igualdad como no discriminación suelen proponer abordajes unidimensionales. Consideran una causa de diferenciación desprovista de razón objetiva de respaldo. Muchas veces, sin embargo, en la realidad no opera un solo factor de discriminación, sino varios, con lo que el problema se complejiza y es más arduo en términos cualitativos. Es el caso, por ejemplo, de mujeres que son excluidas de ciertos puestos o actividades por su condición de mujeres, junto a la que concurre el que sean pobres y afrodescendientes o indígenas. También es el caso de personas privadas de libertad en cárceles, que además sufren pobreza y presentan alguna discapacidad. Estamos, pues, ante lo que se conoce como discriminación múltiple o interseccional ${ }^{26}$.

Los remedios que adoptar en supuestos de este tipo han de estimar, en consecuencia, el entrelazamiento de un conjunto de factores causantes de la situación discriminatoria. Es claro, por ende, que las autoridades estatales deberán adoptar políticas públicas integrales, a menudo con intervención de distintos órganos y en diferentes ámbitos de la realidad, para remover desde las raíces la discriminación multicausal o interseccional.

\subsection{IGUALDAD COMO NO SOMETIMIENTO}

La concepción de la igualdad como no sometimiento no pone el acento en la mera proscripción de tratos desiguales arbitrarios, ni en la esfera individual de las personas, como hace la concepción de la igualdad como mera no discriminación. Antes bien, la visión de la igualdad como no subordinación dirigirá su atención hacia aquellas características que dotan a las personas de identidad por su pertenencia a determinados grupos sociales en situación de desventaja estructural ${ }^{27}$. Y es que algunos colectivos — tales como las mujeres, los migrantes, los pueblos originarios, las minorías sexuales, entre otros- no están en condiciones de paridad para el acceso y disfrute de sus derechos fundamentales, con relación a quienes mantienen una posición hegemónica o de dominación en la sociedad.

Esta «lectura estructural de la desigualdad», como la llama Roberto Saba, afirma que el propósito esencial de la cláusula constitucional de igualdad ante la ley —y de su equivalente en

\footnotetext{
${ }^{25}$ Salomé (2017), p. 262; Díaz de Valdés (2015), p. 164; Huerta (2005), p. 312.

${ }^{26}$ Crenshaw (1991), pp. 1242-1245; Ronconi (2019), p. 126; Rey (2008), pp. 255-257, 263-267; Salomé (2015), pp. 36-41.

${ }^{27}$ Nash y David (2010), pp. 172-173; Clérico y Aldao (2011), pp. 142-143; Añón (2013), pp. 131-132.
} 
los tratados internacionales de derechos humanos- no es solo ni principalmente impedir tratos desiguales carentes de razonabilidad, sino sobre todo evitar el mantenimiento o perpetuación de «grupos sometidos, excluidos o sojuzgados en una sociedad»28. La desventaja estructural, por su propia naturaleza, no puede ser remontada por las personas que pertenecen al grupo mediante acciones individuales. Se requiere, en consecuencia, una intervención estatal compleja, vigorosa y sostenida para remover las causas de la desigualdad, las cuales hun den sus raíces en el modo de organización y funcionamiento de la sociedad. No será suficiente, por lo tanto, con no discriminar, sino que hará falta que las autoridades públicas adopten políticas y medidas para desmontar las barreras estructurales que marginan e impiden a los grupos excluidos alcanzar la igualdad real.

De esta manera, no se presupone la existencia de una situación de paridad como punto de partida, tal cual hicieron los liberales decimonónicos que adhirieron al ideal igualitario del que era portador el constitucionalismo democrático fundacional. Tampoco se asume que lo central y determinante es evitar las distinciones arbitrarias, mediante la ceguera de la ley y de la autoridad pública a las características de las personas individualmente consideradas. En vez de todo ello, se reconoce más bien la inequidad existente de facto, en particular, respecto de grupos en situación de desventaja o vulnerabilidad, y por lo tanto se formula el principio de igualdad como meta a lograr, como aspiración primordial del modelo de Estado constitucional y democrático de Derecho.

Lo que se quiere combatir es, entonces, la injusticia social que sufren determinados colectivos, la misma que con frecuencia se arrastra por varias generaciones. Así, se trata de cambiar la «estructura jerárquica de la sociedad», eliminando todo «sistema de castas» que produzca o conlleve grupos o clases sociales en situación de inferioridad permanente, lo que encuentra justificación en el propósito múltiple de «preservar la paz social», mantener a la comunidad política como «un todo cohesionado» y «permitir el más pleno desarrollo» de los individuos que integran el «grupo subordinado» 29.

Ahora bien, el grupo social en desventaja es tal si es que posee identidad y vida propia. La comunidad lo percibe de ese modo, pero también sus mismos integrantes. Puede, pues, aseverarse que la identidad de sus miembros queda establecida, en gran parte, por su pertenencia al colectivo. De otro lado, el grupo tiene una determinada entidad, en la medida en

${ }^{28}$ Saba (2018), p. 58.

${ }^{29}$ Fiss (1999), pp. 140-141. 
que existe más allá de quienes lo componen y se distingue de estos. No obstante, se observa asimismo una relación de interdependencia entre el grupo y sus miembros, ya que la identidad y el bienestar de ambos - de los sujetos y del colectivo al que pertenecen - se relacionan mutuamente. De esta suerte, «los miembros del grupo se autoidentifican —explican quiénes son- refiriéndose a su condición de miembros del grupo; y su estatus resulta determinado en parte por el estatus del grupo» ${ }^{30}$.

En el caso de los afrodescendientes en Estados Unidos de América, Owen Fiss hace notar la existencia de otros dos rasgos cruciales, a saber, su muy baja posición socioeconómica y el que ese estatus se venga prolongando por siglos ${ }^{31}$. De allí que constituyan una «clase inferior permanente», lo que los hace acreedores a «medidas redistributivas» a manera de compensación, y de allí también que su concomitante escaso poder político requiera reforzar mecanismos, incluyendo acciones judiciales, para hacer oír su voz y mejorar su participación en el proceso de toma de decisiones que se desarrolla en el ámbito de la política ${ }^{32}$. Por su parte, María José Añón Roig ha destacado que la noción de grupo desaventajado no debe ser entendida como una «entidad esencialista o naturalista», que se distinga por «un conjunto específico de atributos comunes», como se aprecia en el caso de las mujeres ${ }^{33}$.

Se sigue, pues, que no podemos hablar de características estáticas o inmutables del colectivo objeto de discriminación estructural o en condiciones de dominación. Además, la configuración del grupo oprimido o marginado responde a una compleja dinámica social, en la que se entremezclan factores económicos, socio-políticos y culturales que tejen una vasta urdimbre que se encuentra arraigada en la estructura de la sociedad. Es claro, por lo demás, que tales elementos distintivos son aplicables a otros colectivos o grupos sociales en situación subordinada y por ello imposibilitados de un ejercicio pleno e igualitario de sus derechos básicos, como es el caso de las personas privadas de libertad en las cárceles del Perú.

En definitiva, tres son los problemas que suelen padecer los grupos sociales en desventaja o especial vulnerabilidad: escasez de medios materiales, falta de reconocimiento y muy pobre representación política ${ }^{34}$. El trabajo pionero de Nancy Fraser destacó que la pobreza o falta de recursos materiales no era la única forma de opresión que sufrían determinados grupos

\footnotetext{
${ }^{30}$ Fiss (1999), pp. 138-139; véanse también, sobre las características del grupo desaventajado, Saba (2018), pp. 55-56; Añón (2013), pp. 132-133; Courtis (2010), p. 113.

31 Fiss (1999), p. 140.

${ }^{32}$ Fiss (1999), pp. 140-141.

33 Añón (2013), p. 133.

${ }^{34}$ Ronconi (2019), p. 128.
} 
excluidos históricamente del igual disfrute de sus derechos básicos. Ella observó tempranamente la necesidad de otra clase de reclamos de justicia social, consistente más bien en reivindicaciones de «reconocimiento», vinculadas a la identidad del grupo y a los valores culturales atribuidos ${ }^{35}$.

Así, la desventaja de determinado grupo puede deberse no tanto o no solo a la carencia de condiciones materiales mínimas, sino también o principalmente a la ausencia o a la insuficiencia de reconocimiento, en el sentido de falta de aprecio o valoración de la diversidad de las identidades. Como dice Luigi Ferrajoli, la cláusula constitucional de igualdad tiene como uno de sus fines principales «la tutela de nuestras diferencias, o lo que es lo mismo, de nuestras diferentes identidades personales» ${ }^{36}$. Precisamente ello es lo que resulta dejado de lado con la omisión de reconocimiento o su retaceo o distorsión.

Se trata, pues, de una injusticia simbólica o cultural, que tiene que ver con patrones de representación o de interpretación de conductas y formas de vida que se apartan de los valores hegemónicos, como puede ocurrir en el caso de las mujeres, las minorías étnicas o lingüísticas, las comunidades LGBTI, los migrantes, entre otros. En todos estos casos, el entendimiento prevaleciente en la esfera cultural construye representaciones, asigna valor o significado, o entiende las conductas y las manifestaciones de culturas sojuzgadas o alternativas desdeñándolas y excluyéndolas ${ }^{37}$. El fenómeno alcanza también al grupo de los presos en el Perú 38 .

La consecuencia de tales prácticas culturales o de simbolización es la marginación de dichos grupos desaventajados de la esfera de la deliberación pública, ya que ni siquiera se los asume como interlocutores válidos. Se les niega una dimensión esencial de reconocimiento como sujetos de igual dignidad y derechos. Desde luego, se afecta con ello también la esfera de la democracia, ya que derivan de allí fuertes restricciones de hecho a la participación en la toma de decisiones en la arena política o en la vida nacional. De ese modo, la falta o debilidad del reconocimiento acarrea una escasa representación o participación política, afectando las bases mismas del modelo de Estado constitucional y democrático de Derecho.

\footnotetext{
35 Fraser (1996), pp. 18-19; Véase también Young (1990), pp. 15-16, 23-24.

${ }^{36}$ Ferrajoli (2019), p. 14.

${ }^{37}$ Clérico et al. (2013), pp. 116, 120 -121; Clérico y Aldao (2011), pp. 143, 152; Rodríguez Gamero (2020), pp. 149, 174-175; Véanse también Nash (2013), p. 25; Salomé (2017), pp. 281-282.

38 Pérez (1994), p. 194; CEAS (2015), p. 18.
} 
Una revaloración de las identidades diversas y de sus manifestaciones y creaciones culturales es, por lo tanto, necesaria para permitir la expresión y la interlocución de los grupos que se hallan bajo condiciones de opresión. En la medida en que sean reconocidos como actores legítimos en la toma de decisiones sociales y políticas, los colectivos subordinados adquirirán poder y mejorarán sus condiciones de vida ${ }^{39}$. Fraser propone por ello, desde su reflexión seminal, el concepto de "paridad participativa», en cuya virtud se puede resolver la falsa dicotomía entre justicia distributiva (económica) y justicia de reconocimiento o simbólica (cultural), integrando ambas dimensiones como necesarias ${ }^{40}$.

Debe recalcarse que, además de este primer requisito de índole objetiva, la paridad participativa exige una precondición «intersubjetiva», en cuya virtud los «modelos culturales de interpretación y valoración» han de permitir «expresar un respeto mutuo para todos los participantes y asegurar la igualdad de oportunidades para conseguir estimación social»41. En consecuencia, se aspira a dejar de lado modelos de interacción despectivos hacia grupos sojuzgados, o fundados en prejuicios o marcos de representación basados en el temor, la incomprensión y aun el odio hacia las identidades diversas ${ }^{42}$.

En trabajos más recientes, Nancy Fraser ha insistido y quizá perfilado con mayor nitidez la dimensión político-participativa de su propuesta. Así, enfocándose principalmente en la situación de las mujeres, dicha autora procura hacer el trazado cartográfico de la imaginación feminista y propugna un recorrido que va de la redistribución al reconocimiento, y de este a la representación ${ }^{43}$. Y en su propuesta académica sobre las escalas de la justicia, en la que aborda los desafíos del nuevo orden de la globalización, asevera que su visión es «tridimensional», ya que «al comprender consideraciones económicas, culturales y políticas, trata la redistribución, el reconocimiento y la representación como tres facetas de la justicia analíticamente distintas, ninguna de las cuales puede ser reducida a las otras, aunque están prácticamente

\footnotetext{
${ }^{39}$ Fiss (1999), pp. 141-142.

${ }^{40}$ Fraser (1996), p. 32.

${ }^{41}$ Fraser (1996), p. 33.

${ }^{42}$ Fiss (1999), p. 141. Al respecto, debe tenerse en cuenta lo que afirma Dworkin (2012a), p. 233, esto es, que «cierta idea de igualdad», a la que denomina «concepción liberal de igualdad», es precisamente «la esencia del liberalismo». Para el filósofo estadounidense, de la igualdad como ideal político liberal derivan dos manifestaciones de principio, a saber, en primer lugar, el requerimiento de que el Gobierno trate como iguales a todas las personas bajo su jurisdicción, es decir, «con el mismo derecho a igual respeto y consideración», y, en segundo lugar, la exigencia de que el Gobierno trate a todos por igual «en la distribuc ión de un recurso de oportunidad» Dworkin (2012a), p. 242. Y en la más famosa de sus obras, al examinar el concepto de derechos contra el Gobierno y si existe un derecho a infringir la ley, Dworkin (2012b), p. 295, afirma que quien tome los derechos en serio debe reconocer una o dos ideas importantes: la idea, «vaga pero poderosa», de la dignidad humana, y la idea, «más familiar», de la igualdad política, que reconoce el mismo respeto y la misma consideración a los miembros más débiles de la comunidad política y a los más poderosos.

${ }^{43}$ Fraser (2010b), p. 100 y ss.
} 
entrelazadas» ${ }^{44}$. También Iris Marion Young, al conceptualizar sus cinco formas de la opresión —explotación, marginación, incapacitación, imperialismo cultural y violencia一, indica que, si bien cada una de ellas puede «comprender o causar injusticias distributivas», no obstante «todas envuelven cuestiones de justicia más allá de la distribución» 45 .

Ahora bien, para superar la discriminación como mecanismo opresivo o de dominación, el medio idóneo es la adopción de acciones afirmativas y políticas públicas integrales, que apunten a remover las causas estructurales de la situación de desventaja que impide a los colectivos concernidos el pleno e igual disfrute o ejercicio de sus derechos fundamentales ${ }^{46}$. Las acciones afirmativas no deberán ser solo reparadoras, sino sobre todo transformadoras ${ }^{47}$. Y las políticas públicas deberán comprometer a un conjunto de instituciones estatales (y, a menudo, también privadas o de la sociedad civil) en intervenciones articuladas y sostenidas.

Las acciones afirmativas reparadoras, siendo indispensables, resultan insuficientes, ya que, al disponer un trato preferente temporal al grupo desaventajado, procuran lograr la igualdad real -o, al menos, la igualdad real de oportunidades-, pero sin que ello implique necesariamente remover las causas sistémicas o sociales de la discriminación ${ }^{48}$. Son, entonces, las acciones afirmativas transformadoras las que deben operar para atacar las raíces de las estructuras sociales discriminatorias. Y es que el objetivo último no ha de ser simplemente lograr un resultado, tal como que las mujeres o los afrodescendientes o indígenas ocupen plazas políticas, sino más bien desmantelar la compleja situación que impide que, en general, los miembros de grupos dominados alcancen puestos de poder en la esfera pública ${ }^{49}$.

Es decir, se trata de atacar el problema de fondo, lo que exige implementar cambios en el «diseño institucional»50. De esta manera, el sistema de cuotas, por ejemplo, es una medida importante, pero hace falta mucho más: es necesario transformar las instituciones y las prácticas de distinta naturaleza -incluyendo elementos económicos, culturales y políticos- para erradicar las condiciones que crean y reproducen la desigualdad y la injusticia51. Tal conceptualización también debe guiar el examen de la situación estructural que padece el

\footnotetext{
${ }^{44}$ Fraser (2010a), p. 365, traducción mía.

45 Young (1990), p. 40, traducción mía.

${ }^{46}$ Nash y David (2010), pp. 180-181; Giménez (2004), pp. 316-326; Eguiguren (2002), pp. 100, 110; Defensoría del Pueblo (2007), pp. 41-46.

${ }^{47}$ Ronconi (2019), pp. 131, 133; Clérico et al. (2013), p. 116; Véase también Rodríguez (2020), p. 150.

${ }^{48}$ Ronconi (2019), pp. 133-134.

${ }^{49}$ Ronconi (2019), p. 134.

${ }^{50}$ Ronconi (2019), p. 134.

${ }^{51}$ Ronconi (2019), pp. 134-135.
} 
colectivo de los reclusos, considerando además las diferencias internas del universo de personas privadas de libertad, el cual es muy variado.

\section{Igualdad de personas privadas de libertad en cárceles: el marco normativo primordial aplicable en el Perú}

Ante todo, resultan aplicables a la situación de los derechos fundamentales de las personas privadas de libertad en centros penitenciarios las cláusulas constitucionales que consagran el principio/derecho de igualdad de todos ante la ley, así como el derecho de los internos a ser recluidos en «establecimientos adecuados» y la indicación de la finalidad resocializadora como la propia del régimen penitenciario (artículos 2.2, 139.21 y 139.22, Const.).

En términos generales, puede decirse que la estipulación de la igualdad en la vigente Constitución peruana de 1993 es escueta y de contenido tradicional, al no haber proscrito de modo expreso diversas modalidades discriminatorias, y al no haber recogido disposiciones que regulen el deber del Estado de remover las causas y condiciones de discriminación o exclusión estructural $^{52}$. No obstante, la jurisprudencia del Tribunal Constitucional ha hecho un amplio desarrollo en el campo del derecho/principio de igualdad, de suerte que ha acogido no solo la distinción entre igualdad formal y material, o el concepto de igualdad de oportunidades, o modalidades como discriminación indirecta y discriminación múltiple, sino que también ha admitido que forman parte de los mandatos de la igualdad constitucional las acciones positivas que procuran alcanzar la igualdad real de colectivos desaventajados o en situación de especial vulnerabilidad 53 .

Como quiera que fuere, debe mencionarse asimismo que el DIDH prevé regulaciones sobre el derecho a la igualdad de los reclusos, las cuales se incorporan a las normas constitucionales en vigor en el país. Ello ocurre por vía doble, ya que la Norma Suprema peruana reconoce máximo rango jurídico a los tratados de derechos humanos y también señala que los instrumentos

\footnotetext{
52 Por contraste, el artículo 13.2 de la Constitución de Colombia (de 1991) estatuye que «el Estado promoverá las condiciones para que la igualdad sea real y efectiva y adoptará medidas a favor de grupos discriminados o marginados», en tanto que el inciso 3 de esta misma disposición constitucional establece que «el Estado protegerá especialmente a aquellas personas que por su condición económica, física o mental, se encuentren en circunstancias de debilidad manifiesta y sancionará los abusos o maltratos que contra ellas se cometan». Puede consultarse la Constitución de Colombia en el sitio web de la Corte Constitucional: [Disponible en: https://bit.ly/3BSvG1r]. Véase también Bernal (2005), p. 258, incluyendo las notas 10 y 11.

Por su parte, también con un desarrollo mucho mayor que en la Carta peruana de 1993, el artículo 3 de la Constitución de Ital ia (de 1947) prevé que «corresponde a la República suprimir los obstáculos de orden económico y social que, limitando de hecho la libertad y la igualdad entre los ciudadanos, impiden el pleno desarrollo de la persona humana y la participación efectiva de todos los trabajadores en la organización política, económica y social del país». Puede consultarse la Constitución italiana en el sitio web del Senado de la República: [Disponible en: https://bit.ly/3faZKLQ]. Véase también Ferrajoli (2019), pp. 13-14.

${ }^{53}$ Salomé (2015), pp. 18-35; Huerta (2005), pp. 318-327.
} 
internacionales en esta materia concurren en la interpretación de los derechos y libertades que la Constitución reconoce, por lo que los correspondientes artículos del Pacto Internacional de Derechos Civiles y Políticos (PIDCP) y de la CADH — artículo 10 y artículo 5, respectivamenteson aplicables como parte del «bloque de constitucionalidad» ${ }^{54}$.

Es más, en sus sentencias, la alta Corte de la constitucionalidad invoca a menudo disposiciones o pronunciamientos del DIDH que no son de naturaleza formalmente vinculante: informes, recomendaciones, principios o documentos de soft law. El Tribunal los emplea como elementos de refuerzo argumentativo o porque dotan de contenido o coadyuvan a la interpretación de enunciados genéricos del marco normativo constitucional y de Derecho Internacional ${ }^{55}$.

\section{La jurisprudencia del Tribunal Constitucional peruano sobre el derecho/principio de igualdad de personas privadas de libertad en centros penitenciarios}

El máximo intérprete de la Constitución en el Perú ha recogido, en su jurisprudencia sobre los derechos fundamentales de las personas privadas de libertad, las dos concepciones de la igualdad constitucional antes expuestas (véase acápite II, supra). Así, ciertas sentencias reflejan la visión de la igualdad como mera no discriminación. En tales sentencias, el enfoque del Tribunal Constitucional es el clásico, es decir, el de la igualdad como no arbitrariedad, como exclusión de distinciones desprovistas de causa objetiva y razonable, el cual se valida en términos individuales, caso por caso.

Otras sentencias, empero — ciertamente más cercanas en el tiempo-, son expresión, aunque todavía incipiente, de la concepción de la igualdad como no sometimiento o no dominación de grupos en desventaja o en situación de especial vulnerabilidad. En estas causas, el Tribunal muestra un mayor nivel de conciencia del problema estructural e histórico que impide al colectivo de las personas privadas de libertad en el sistema carcelario peruano el pleno e igual disfrute o ejercicio de sus derechos fundamentales. Son, sobre todo, los casos en los que el supremo intérprete de la Constitución ha declarado el «estado de cosas inconstitucional» en relación a las condiciones de reclusión penitenciaria que lesionan la dignidad humana.

\footnotetext{
${ }^{54}$ Hakansson (2009), pp. 180, 234-238; Landa (2006), pp. 119-121; Sentencia del Tribunal Constitucional N² 2730-2006-PA, del 21 de julio de 2006, fundamentos 9-15

55 Torres (2013), pp. 362-363.
} 


\subsection{TRIBUNAL CONSTITUCIONAL, DERECHOS FUNDAMENTALES DE RECLUSOS E IGUALDAD COMO NO DISCRIMINACIÓN}

Los procesos en los que se pone de manifiesto la concepción de la igualdad como no discriminación son diversos. De un lado, hay sentencias en las que el Tribunal valida las medidas adoptadas por las autoridades carcelarias, las cuales no incurren en discriminación, como sucede con relación a los traslados de los internos de una prisión a otra, o como acontece respecto de las limitaciones previstas por el legislador para reconocer u otorgar beneficios penitenciarios a quienes han cometido determinados delitos.

\subsubsection{Los traslados carcelarios}

La cuestión de los traslados de un centro carcelario a otro ha sido abordada en varios procesos de habeas corpus por el Tribunal Constitucional. El primero a comentar es el caso Rodríguez Medrano, resuelto en junio del año 2002, en el cual se cuestiona el traslado del detenido desde el establecimiento penal San Jorge al centro penitenciario Castro Castro.

La demanda, además de alegar la vulneración de diversos derechos fundamentales vinculados a las condiciones de reclusión -lo que será objeto de análisis más adelante (véase el acápite IV.2.1, infra)—, solicita la transferencia del interno de regreso a San Jorge. Sostiene, al respecto, que el nuevo recinto constituye un penal de máxima seguridad, donde la vida y la integridad física del beneficiario del habeas corpus corren peligro, ya que, al tratarse de un exjuez, podría ser agredido por «personas que fueron sentenciadas por él cuando ejercía funciones jurisdiccionales» ${ }^{56}$. Por su parte, la autoridad carcelaria adujo que el traslado respondía a la necesidad de brindar mayor seguridad al detenido, y que no tenía la obligación de consultarle sobre ello, como este reclamaba ${ }^{57}$.

Al resolver el punto, el Tribunal Constitucional sostuvo, ante todo, que «el traslado de los internos de un establecimiento penal a otro no es en sí mismo un acto inconstitucional» (fundamento 16). Desestimando los argumentos del reclamante, el Tribunal enfatizó la obligación de la administración penitenciaria de velar por la vida e integridad física de los reclusos, así como por todos aquellos derechos fundamentales no restringidos por la medida de prisión preventiva a la que estaba sujeto el detenido (fundamento 16).

\footnotetext{
${ }^{56}$ Sentencia del Tribunal Constitucional $\mathrm{N}^{\circ}$ 0726-2002-HC, de 21 de junio de 2002, antecedentes, párrafo 3.

${ }^{57}$ Sentencia del Tribunal Constitucional № 0726-2002-HC, de 21 de junio de 2002, antecedentes, párrafo 3 y fundamento 15.
} 
Es interesante observar que la alta Corte de la constitucionalidad, en esta decisión temprana, enuncia elementos del test de proporcionalidad. Así, afirma que «dentro de márgenes sujetos al principio de razonabilidad», la autoridad carcelaria no solo puede, sino que debe adoptar las «medidas estrictamente necesarias» para salvaguardar los derechos constitucionales de los internos (fundamento 16). El Tribunal considera también que en el caso han existido «razones objetivas», las cuales quedaron plasmadas en la Resolución Directoral N 924-2001-INPE/17, que ordenó el traslado de diversos internos, entre los que se hallaba el exmagistrado Rodríguez Medrano, ya que se procuraba garantizar la vida e integridad de los trasladados, pues en el penal San Jorge no existían condiciones mínimas para ello (fundamento 17).

El Tribunal estimó además que la medida no era «irrazonable», pues tenía como sustento sendas notas informativas y de inteligencia que advertían de amenazas contra la vida e integridad del beneficiario del habeas corpus (fundamento 17). En consecuencia, el supremo intérprete de la Constitución, tras constatar que existía «congruencia» entre los motivos y las medidas adoptadas, determinó que «no es arbitrario el traslado del actor de un establecimiento penal a otro» (fundamento 19).

En realidad, la demanda contenía una petición de trato diferente doble: de un lado, al resistirse al traslado del interno desde el penal San Jorge al penal Castro Castro, y, de otro lado, al exigir que fuera conducido nuevamente al centro de detención de origen. Si bien el Tribunal no aborda la cuestión de manera explícita, parece claro que no considera que exista un tratamiento selectivo injustificado al transferir al exjuez Rodríguez Medrano de una prisión a otra, para lo que construye una argumentación constitucional fundada en que se ha respetado el principio de razonabilidad, evitando así cualquier acto arbitrario. Por lo demás, el máximo órgano jurisdiccional tampoco encuentra sustento constitucional a la exigencia de que el detenido fuera trasladado de retorno al centro carcelario original, lo que ciertamente hubiera significado conceder un privilegio indebido y contrario a la Carta fundamental (tratamiento diferente injustificado, por carecer de causa objetiva y razonable).

Posteriormente, en noviembre de aquel mismo año 2002, el Tribunal Constitucional volvió a ocuparse de la cuestión de los traslados de las personas privadas de libertad. En el caso Islas Trinidad y otros se planteó, entre diversos asuntos, la constitucionalidad del traslado de un conjunto de 34 reclusos desde el penal de Yanamayo (en Puno) hacia el penal de Challapalca (en Tacna), alegándose por los reclamantes que el nuevo centro de reclusión — situado, como se 
sabe, a una altitud superior a los 4,200 metros sobre el nivel del mar-imponía condiciones que vulneraban los derechos básicos de los presos ${ }^{58}$.

Si bien la cuestión central del caso tenía relación nuevamente con las condiciones de reclusión, y en particular con el derecho a la salud de los internos - temas que serán abordados después (véase el acápite IV.2.1, infra)—, el Tribunal examinó nuevamente el asunto de las transferencias de reclusos. En esta oportunidad, el guardián de la Constitución validó una Directiva del Instituto Nacional Penitenciario (INPE) que regulaba la potestad de trasladar a los presos «por reordenamiento» en aquellos casos en los que «la capacidad de albergue de un Establecimiento Penitenciario es excedida por el número de internos que actualmente presenta dicho Establecimiento, poniendo en riesgo el régimen y disciplina penitenciaria» ${ }^{9}$. Es decir, se trataba de traslados vinculados a la problemática de la sobrepoblación y el hacinamiento.

El Tribunal consideró que la mencionada Directiva (norma administrativa interna) no infringía los principios constitucionales, en la medida en que regulaba los supuestos habilitantes de la mudanza y la autoridad competente para realizarla, para lo que sostuvo que tales aspectos «no inciden directamente en los derechos de las personas recluidas en un establecimiento penal y en los principios constitucionales del régimen penitenciario»60. La alta Corte aseveró, en consecuencia, que carecía de sentido evaluar si el acto administrativo que ordenó el cambio de Yanamayo a Challapalca «respetó o no el principio de razonabilidad en cuanto límite y parámetro de la validez constitucional de las potestades administrativas» (fundamento 17).

Esta vez, los accionantes afirmaron también que la medida de traslado respondía al propósito de separar a los reclusos no solo de sus familiares sino de toda la sociedad, «en aplicación de un plan de aislamiento, aniquilamiento y genocidio iniciado por el anterior gobierno»61. Este lenguaje, ciertamente, es el mismo enarbolado por los presos de Sendero Luminoso, organización subversiva y terrorista, según se aprecia en diversos estudios ${ }^{62}$. La Defensoría del Pueblo, por lo demás, señaló en su informe del año 2003 que los delitos imputados a los internos de Challapalca eran por lo general delitos contra el patrimonio y terrorismo ${ }^{63}$. No obstante, al margen de la enérgica condena que merecen los crímenes del senderismo y el enorme daño

\footnotetext{
${ }^{58}$ Sobre los cuestionamientos a la excesiva altitud, rigor climático y aislamiento de la cárcel de Challapalca, así como a sus severas condiciones de encierro de los internos, véase CIDH (2003); Defensoría del Pueblo (2003).

${ }^{59}$ Sentencia del Tribunal Constitucional N 1429-2002-HC, de 19 de noviembre de 2002, fundamento 16.

${ }^{60}$ Sentencia del Tribunal Constitucional No 1429-2002-HC, de 19 de noviembre de 2002, fundamento 17.

${ }^{61}$ Sentencia del Tribunal Constitucional N 1429-2002-HC, de 19 de noviembre de 2002, antecedentes, párrafo 2.

62 Zapata (2017), pp. 172-175; Comisión de la Verdad y Reconciliación (2003), pp. 681-683, 711-714.

${ }^{63}$ Defensoría del Pueblo (2003), p. 12.
} 
causado al Perú, se trataba de un argumento que denunciaba un supuesto tratamiento especial a cierto grupo de presos con la finalidad de apartarlo o excluirlo de la sociedad mediante su encierro carcelario bajo «condiciones de reclusión inhumanas, humillantes y degradantes, incompatibles con la dignidad de persona humana» ${ }^{64}$.

Ahora bien, en este caso, las razones esgrimidas por el Tribunal Constitucional para desestimar el reclamo relativo al traslado forzoso ordenado por la autoridad penitenciaria resultan harto discutibles. La alta Corte evita pronunciarse sobre si los internos tienen fundamento constitucional para oponerse al cambio de centro carcelario. El escamoteo de la cuestión constitucional relevante es muy endeble, al apoyarse en la naturaleza administrativa de la Directiva, como fuente legal a la que le está vedado regular materias relativas a derechos fundamentales o principios constitucionales. Esto es más notorio si se repara en que, como ya ha sido indicado aquí, la Resolución que dispuso el traslado aplicó la Directiva mencionada, la cual preveía el traslado de internos «por reordenamiento», en caso de sobrepoblación o hacinamiento que pusiera en peligro «el régimen y disciplina penitenciaria» (fundamento 16).

El supremo intérprete de la Constitución, sin embargo, se rehusó a pronunciarse sobre la cuestión sustantiva del traslado, escudándose en una razón de orden adjetivo menor. Hubiera sido importante que el Tribunal Constitucional dejara esclarecido el punto acerca de si existía un tratamiento diferente injustificado hacia un grupo de reclusos al trasladarlos a un penal con la supuesta finalidad de afectar sus derechos fundamentales, sometiéndolos a condiciones de internamiento inhumanas e indignas.

\subsubsection{Los beneficios penitenciarios}

El Tribunal Constitucional peruano ha examinado si la prohibición legal de concesión de beneficios penitenciarios por determinados delitos infringe el derecho/principio de igualdad. El lineamiento jurisprudencial fue establecido en el proceso de inconstitucionalidad seguido contra la legislación antiterrorista aprobada durante el Gobierno del presidente Alberto Fujimori. El supremo intérprete de la Constitución decidió entonces que no había trato discriminatorio, aplicando para ello los criterios tradicionales de la concepción de la igualdad como no discriminación.

${ }^{64}$ Sentencia del Tribunal Constitucional ํ1429-2002-HC, de 19 de noviembre de 2002, antecedentes, párrafo 2. 
Al respecto, el artículo 19 del Decreto Ley 25475, emitido el 5 de mayo de 1992, había estipulado que «los procesados o condenados por delitos de terrorismo no podrán acogerse a ninguno de los beneficios que establecen el Código Penal y el Código de Ejecución Penal». El Tribunal sostuvo que el punto controvertido consistía en determinar la compatibilidad de dicha exclusión con el principio de igualdad jurídica. Así, consideró que la cuestión constitucional surge cuando el legislador democrático prevé los beneficios penitenciarios para quienes son condenados por ciertos delitos, pero a la vez «los niega para los condenados por otros» 65 .

El guardián de la Carta Fundamental recordó su doctrina, bien asentada, en el sentido que la ley puede introducir diferenciaciones, pero a condición de que respondan a causas «objetivas y razonables» (fundamento 211). El máximo órgano de la jurisdicción constitucional afirmó que la prohibición que contiene la Constitución no es a la diferencia, sino a su establecimiento arbitrario «por no poseer un elemento objetivo que la justifique o una justificación razonable que la respalde» (fundamento 211). En definitiva, el Tribunal desestimó que la no concesión de beneficios penitenciarios a los condenados por haber perpetrado actos terroristas colisionara per se con el principio de igualdad, estatuyendo que tal tratamiento legal se encuentra justificado «en atención a la especial gravedad del delito en cuestión y a los bienes de orden público constitucional que, con su dictado, se persigue proteger» (fundamento 211).

Más discutible parece, sin embargo, la argumentación de la alta Corte de la constitucionalidad para sostener que el legislador tiene la potestad de autorizar la concesión de beneficios penitenciarios, como una derivación de la finalidad resocializadora de las penas contemplada en la Constitución, pero que no se desprende del artículo 139.22 de la Carta «un mandato al legislador para que los prevea», cuya «ausencia, negación u omisión» pudiera configurar un «vicio de inconstitucionalidad» (fundamentos 208 y 209).

De cualquier modo, el Tribunal observó asimismo que, en el caso concreto bajo examen, la restricción legal al acceso a los beneficios penitenciarios para los condenados por terrorismo no tenía carácter general, sino que únicamente se refería a aquellos regulados en dos cuerpos normativos específicos, a saber, el Código Penal y el Código de Ejecución Penal, de suerte que estaba abierta la posibilidad de que la ley otorgase beneficios penitenciarios a quienes purgaban pena por la mencionada figura delictiva (fundamento 212).

${ }^{65}$ Sentencia del Tribunal Constitucional № 010-2002-AI, de 3 de enero de 2003, fundamento 210. 
El supremo intérprete de la Constitución volvió a ocuparse de los beneficios penitenciarios con relación al mandato constitucional de igualdad en el caso de los Decretos Legislativos 921 a 927, aprobados precisamente tras la emisión de la sentencia sobre la legislación antiterrorista, para reemplazar a esta bajo pautas propias del Estado constitucional y democrático de Derecho. El Tribunal rechazó la objeción de invalidez constitucional, señalando que el establecimiento de «reglas ad hoc» para sentenciados por haber cometido actos terroristas no se sustentaba en «razones discriminatorias o de orden político»66.

En esta sentencia, la alta Corte de la constitucionalidad desarrolla de manera detallada la aplicación del test de igualdad, como modalidad o derivación del test de proporcionalidad, dividiéndolo en seis pasos: determinación del tratamiento legislativo diferente o intervención en la igualdad, determinación de la intensidad de tal intervención, determinación de la finalidad del trato distinto, y luego los tres exámenes clásicos de idoneidad, necesidad y proporcionalidad en sentido estricto o ponderación (fundamentos 323-341).

Si bien el Tribunal Constitucional validó como no discriminatorio un régimen restrictivo de beneficios penitenciarios para reclusos por terrorismo, distinto del régimen general para todo otro tipo de delitos, con una fundamentación respetuosa de los cánones constitucionales, parece en cambio muy polémica su doctrina, reafirmada en esta causa, acerca de que los beneficios penitenciarios no son derechos fundamentales —esto es, de rango constitucional一, sino derechos de carácter meramente legal (fundamento 326). El máximo órgano jurisdiccional avanza al considerar que los beneficios penitenciarios tienen la naturaleza de «derechos subjetivos condicionados», conforme a las corrientes doctrinales, legislativas y jurisprudenciales más recientes, como en el caso de España ${ }^{67}$. No obstante, no resulta convincente la afirmación del carácter meramente legal de los beneficios que son propios de la ejecución penitenciaria, ya que estos pueden ser derivados como derechos fundamentales de la finalidad resocializadora de la pena, consagrada de manera expresa como derecho y principio de la función jurisdiccional (artículo 139.22, Const.), en armonía con la cláusula constitucional de derechos fundamentales implícitos (artículo 3, Const.).

Es de destacar que, a propósito de este tema, Diana Milla ha reparado en la relevancia de la evolución de la jurisprudencia del Tribunal Constitucional, que lleva a recusar que «ciertas

\footnotetext{
${ }^{66}$ Sentencia del Tribunal Constitucional № 003-2005-PI, de 9 de agosto de 2006, fundamento 321.

${ }^{67}$ Milla (2019), pp. 251-252, 254, 262.
} 
minorías o grupos sociales en desventaja puedan quedar aislados y $\sin$ voz» ${ }^{68}$. En consecuencia, afirma esta estudiosa que la nueva concepción del derecho fundamental a la igualdad se erige en «auténtico punto de inflexión», en la medida en que su dimensión sustantiva exige brindar a todas las personas las mismas oportunidades para el goce de sus derechos fundamentales, por lo que:

«todos los sentenciados, sin excepción (condicionados al cumplimiento de ciertos requisitos objetivos), debieran tener abierta la posibilidad a la resocialización y, por ende, acceder a los beneficios penitenciarios sin mayor limitación que la propia voluntad de los internos, quedando el quantum de la pena con relación a los ilícitos en la vía judicial y no en la penitenciaria» ${ }^{69}$.

\subsection{TRIBUNAL CONSTITUCIONAL, DERECHOS FUNDAMENTALES DE RECLUSOS E IGUALDAD COMO NO DOMINACIÓN: DEL HABEAS CORPUS CORRECTIVO AL ESTADO DE COSAS INCONSTITUCIONAL}

Como ya se ha dicho, una de las principales características de la concepción de la igualdad como no dominación o no sometimiento es que pone el acento en la dimensión colectiva del problema. Yendo más allá de la solución de casos individuales de discriminación por arbitrariedad, este enfoque se pregunta por las causas que subyacen a las estructuras de la sociedad y que son las que determinan una situación general de exclusión del disfrute o ejercicio de derechos fundamentales para enteros grupos sociales que se hallan en desventaja o especial vulnerabilidad con relación al resto de la sociedad o a sectores hegemónicos o dominantes dentro de ella. Así, respecto del grupo de personas privadas de libertad en centros penitenciarios peruanos, por ejemplo, la cuestión clave no será atender el problema de tal o cual recluso que puede ver vulnerado el goce o ejercicio igualitario de algunos de sus derechos básicos, sino modificar las condiciones de opresión estructural que llevan a que el colectivo al que pertenece experimente una violación sistemática y generalizada de derechos fundamentales.

En el Perú, la visión de la igualdad como no subordinación ha alcanzado reconocimiento parcial, en fecha reciente, en la jurisprudencia del Tribunal Constitucional, si bien con ciertas limitaciones ${ }^{70}$. En el ámbito de la realidad carcelaria, sin embargo, hay avances importantes pero

\footnotetext{
${ }^{68}$ Sentencia del Tribunal Constitucional N 0033-2010-PI, de 10 de abril de 2012; Milla (2019), p. 315.

${ }^{69}$ Milla (2019), p. 316.

${ }^{70}$ Sentencia del Tribunal Constitucional N 01272-2017-PA, de 5 de marzo de 2019, fundamentos 12-13; Sentencia del Tribunal Constitucional $\mathrm{N}^{\circ}$ 00853-2015-PA, de 14 de marzo de 2017, fundamento 58; para un análisis crítico, en particular en relación a personas con discapacidad mental, véase Rodríguez (2020), pp. 149, 183-196.
} 
aún incipientes, y queda un largo camino por recorrer ${ }^{71}$. De cualquier modo, es interesante observar la evolución que ha llevado al guardián de la Constitución desde la creación y desarrollo del «habeas corpus correctivo» hasta la declaración del «estado de cosas inconstitucional», como las instituciones que han impulsado el cambio progresivo en la tutela igualitaria otorgada a la población de reclusos en sede de jurisdicción constitucional.

Y es que las sentencias que acogieron una modalidad específica de proceso constitucional (el habeas corpus «correctivo») para impedir la lesión de los derechos humanos de los presos fueron una primera manera de aproximarse a los problemas generales de la realidad penitenciaria del país y de ir, de manera paulatina, proyectando las decisiones del Tribunal Constitucional más allá de los casos concretos resueltos cada vez. Posteriormente, el empleo de la figura del «estado de cosas inconstitucional», tomada de la jurisprudencia desarrollada por la Corte Constitucional colombiana ${ }^{72}$, servirá para dar nuevos pasos sustantivos en la ruta de extender la protección jurisdiccional al colectivo de los reclusos bajo una lógica que procura atacar los problemas estructurales.

Cabe poner de relieve que la técnica de declarar un «estado de cosas inconstitucional»se vincula también al litigio estratégico de Derecho Público, y supone una serie de características que modifican el enfoque tradicional sobre los procesos judiciales. De hecho, en el nuevo modelo el punto central del proceso ya no estará en el daño individual, sino en las condiciones sociales que lo posibilitan y reproducen, mientras que la víctima y beneficiario de la acción judicial ya no será una persona, sino un grupo que comparte una posición de vulnerabilidad. Otras características son que el órgano jurisdiccional deberá abandonar el rol pasivo de quien debe meramente declarar cuál de las partes tiene la razón, para asumir un papel activo que conduzca a la solución de un problema social o estructural complejo, así como que la etapa de los remedios o reparaciones será crucial y normalmente prolongada, pues la jurisdicción del tribunal, en fase de supervisión, habrá de mantenerse en tanto persista el problema que dio origen al litigio ${ }^{73}$.

\subsubsection{El habeas corpus correctivo por condiciones de reclusión}

\footnotetext{
${ }^{71}$ La Corte IDH también ha acogido, al cabo de una larga evolución que aún no concluye, la concepción de la igualdad como no sometimiento de grupos en desventaja o especial vulnerabilidad por causas estructurales, como puede apreciarse en varios pronunciamientos relativos, por ejemplo, a migrantes, mujeres y población LGBTI (Corte IDH (2003), párrafo 103; Corte IDH. Caso Gonzálezy Otras ("Campo Algodonero») vs. México. Sentencia de 16 de noviembre de 2009, párrafos 401, 450; Corte IDH. Caso Atala Riffo y niñas vs. Chile. Sentencia de 24 de febrero de 2012, párrafos 79, 80, 92, 267). No obstante, tales avances no se reflejan todavía en decisiones sobre los derechos fundamentales de los presos y sobre las condiciones de reclusión que sufren (Corte IDH. Caso Chinchilla Sandoval y otros vs. Guatemala. Sentencia de 29 de febrero de 2016). Véanse también Saba (2018), pp. 67-79; Nash y David (2010), pp. 167-179; Castro (2018), pp. 35-54.

${ }^{72}$ Ramírez (2013), pp. 5-6, 13-19, 59; Sánchez (2020), pp. 147-151.

${ }^{73}$ Ramírez (2013), pp. 107-128; Fiss (2007), pp. 38-49; véase también Bustamante (2011), pp. 8-22, 93-98.
} 
El habeas corpus correctivo fue admitido por primera vez por el Tribunal Constitucional en el año 2001, cuando aún se hallaba en vigor la vieja Ley 23506, denominada «Ley de Habeas Corpus y Amparo» (del año 1982), antes de la entrada en vigencia del Código Procesal Constitucional (del año 2004), que con algunas modificaciones se mantiene hasta hoy. En dicha oportunidad, si bien el Tribunal consideró que existía un vicio procesal que obligaba a declarar nulo lo actuado y a reponer la causa al estado de admitir la demanda a trámite, también estableció que los reclamantes no cuestionaban la sentencia que los había condenado, sino más bien «las condiciones de reclusión bajo las que se encuentran» ${ }^{74}$.

En esta línea de razonamiento, el máximo órgano jurisdiccional estableció que, puesto que la pretensión consistía en que «cesen las condiciones de reclusión» —que la demanda calificaba de «inhumanas, humillantes y degradantes», por imponer la incomunicación y el aislamiento absoluto y permanente de los internos-, se configuraba un «habeas corpus correctivo» (fundamento 3). El Tribunal estatuyó que este procedía en el siguiente supuesto, definido con amplitud con relación a los derechos afectados y a los centros de privación de la libertad:

[...] ante la amenaza o acto lesivo del derecho a la vida, la integridad física y psicológica o el derecho a la salud de las personas que se hallan recluidas en establecimientos penales e incluso de personas que, bajo una especial relación de sujeción, se encuentran internadas en establecimientos de tratamiento, públicos o privados (fundamento 3).

Debe destacarse que, ya en esta primera resolución, la alta Corte de la constitucionalidad, en aplicación del marco normativo entonces en vigor (la Primera Disposición General de la Ley Orgánica del Tribunal), fijó como principio de observancia obligatoria para todos los jueces el alcance general del habeas corpus correctivo por condiciones de reclusión en los diversos ámbitos de privación de libertad (fundamento 3). De este modo, la decisión proyectaba sus efectos más allá del caso concreto.

Desde luego, no es un detalle menor que el supremo intérprete de la Constitución haya realizado este desarrollo jurisprudencial sin que existiera para ello base normativa expresa ${ }^{75}$. Se trató, pues, de una construcción judicial que procuraba una mejor protección de los derechos fundamentales de los reclusos. La resolución, por lo demás, como se acaba de indicar, procuraba también tener un alcance general76.

\footnotetext{
${ }^{74}$ Resolución del Tribunal Constitucional $\mathrm{N}^{\circ}$ 0590-2001-HC, de 22 de junio de 2001, fallo y fundamento 2 .

${ }^{75}$ Huerta (2008), p. 94.

${ }^{76}$ En la actualidad, la figura del habeas corpus correctivo ha sido recogida en el Código Procesal Constitucional, que señala su procedencia para la protección del «derecho del detenido o recluso a no ser objeto de un tratamiento carente de razonabilidad y proporcionalidad, respecto de la forma y condiciones en que cumple el mandato de detención o la pena» (artículo 25.17). Su or igen,
} 
Un paso adelante en la evolución jurisprudencial sobre la materia fue dado el siguiente año, 2002, con ocasión del habeas corpus del exjuez Rodríguez Medrano, comentado antes en relación al tema de los traslados. En la demanda se alegó que el recluso ocupaba «un ambiente semejante a una jaula», de apenas doce metros cuadrados para tres camarotes asignados a seis internos, y que no contaba con ducha ni servicios higiénicos ni agua, lo que era considerado como un trato infrahumano ${ }^{77}$.

El Tribunal Constitucional confirmó que el habeas corpus correctivo habilitaba el control constitucional de «las condiciones en las que se desarrolla la restricción del ejercicio de la libertad individual, en todos aquellos casos en que esta se haya decretado judicialmente» (fundamento 2). Esto incluía, desde luego, los supuestos de prisión preventiva -la sentencia le llamó «detención preventiva ordenada por el juez»-, a los efectos de verificar que la medida cautelar respetase «los principios y valores constitucionales», en particular, «el derecho de dignidad de la persona, y los principios de razonabilidad y proporcionalidad» (fundamento 3).

Ahora bien, el Tribunal señaló importantes pautas interpretativas sobre el derecho de los reclusos a no ser objeto de tratos inhumanos, indicando su estrecha relación con la «dignidad» personal y con el derecho a la «vida digna», ambos de naturaleza constitucional (fundamentos 8 y 9). El máximo órgano jurisdiccional enfatizó que estos derechos proscriben la restricción de la libertad individual «en condiciones de hacinamiento o postración en ambientes pequeños, donde se carezca de las mínimas e indispensables estructuras de higiene, instalaciones sanitarias, entre otros aspectos», remitiéndose a las Reglas Mandela (fundamento 9).

Todavía más, resulta muy relevante en esta decisión pionera que la alta Corte de la constitucionalidad se haya rehusado a evaluar las condiciones de reclusión «considerando la situación de un interno en forma aislada», para más bien proponer la necesidad de examinar, a la vez, «las condiciones en las que los demás internos (procesados o sentenciados) de un mismo establecimiento penal se encuentran» (fundamento 10). En consecuencia, el Tribunal Constitucional estima que el derecho a no ser objeto de tratos inhumanos tiene, además de una faz negativa o reaccional, que pone límites al Estado, una vertiente positiva, que exige de las autoridades públicas competentes el diseñar y llevar a la práctica medidas orientadas a

sin embargo, parece estar en el Derecho Constitucional argentino, primero en su jurisprudencia y luego, en fechas recientes, en la modificación constitucional de 1994 (artículo 43) y en la Ley 23.098 (artículo 3.2), Sagüés (1998), pp. 203-205.

77 Sentencia del Tribunal Constitucional $N^{\circ} 0726-2002-\mathrm{HC}$, de 21 de junio de 2002, antecedentes, párrafo 2. 
«remover los obstáculos que de hecho impiden el ejercicio irrestricto de los derechos de los reclusos» (fundamento 10 ).

Como se puede apreciar, estos conceptos enunciados por el Tribunal Constitucional abonaban el terreno para considerar eventuales violaciones de derechos básicos de los reclusos desde una perspectiva colectiva y que coloca el acento en los deberes positivos del Estado. En tal sentido, al margen de que la demanda fuera desestimada ya que el presunto acto lesivo había cesado, son las autoridades públicas las que se ven conminadas a realizar acciones para desmontar las estructuras que obstaculizan de facto el ejercicio de los derechos fundamentales de los presos.

En la posterior jurisprudencia del Tribunal Constitucional la problemática de las condiciones de reclusión violatorias de la dignidad personal vuelve a aparecer repetidamente, asociada ahora a reclamos en defensa del derecho a la salud. Así, en el caso Islas Trinidad y otros se discutió, como ya ha sido indicado aquí, el traslado de un grupo de reclusos al penal de Challapalca, situado por encima de los 4,200 metros sobre el nivel del mar, en condiciones climáticas y de aislamiento muy severas. La controversia giró alrededor de si las condiciones de reclusión afectaban el derecho de los internos a no ser víctimas de tratos inhumanos o degradantes y su derecho a la salud (fundamento 3).

Ante todo, el guardián de la Constitución, guiándose por la jurisprudencia del TEDH (caso Tyrer y caso Irlanda vs. Reino Unido), distinguió los tratos inhumanos de los tratos degradantes. Por los primeros se entiende aquellos que causan a las personas «sufrimientos de especial intensidad», mientras que los segundos acarrean «humillación o una sensación de envilecimiento de un nivel diferente y mayor al que ocasiona la sola imposición de una condena» ${ }^{78}$. Dados estos conceptos, el Tribunal consideró que el presunto acto lesivo situaba la controversia en el terreno de los «tratos inhumanos» (fundamento 8).

Debe resaltarse que el Tribunal Constitucional enunció el especial valor del derecho a la salud en el plexo de los derechos fundamentales y lo asoció directamente con los derechos a la vida y a la integridad personal, y con el principio de dignidad, lo cual afirmaba su fundamentalidad indiscutible, a pesar de la ubicación sistemática del artículo 7 de la Carta, consagratorio del citado derecho a la salud, que, como se sabe, no forma parte del capítulo I del Título I de la Constitución, cuyo epígrafe reza «Derechos fundamentales de la persona». En particular, el

${ }^{78}$ Sentencia del Tribunal Constitucional N²1429-2002-HC, de 19 de noviembre de 2002, fundamento 7, párrafo 2. 
Tribunal aseveró que el derecho a la salud se erige en «condición necesaria» del ejercicio del derecho a la «vida digna» y que, en determinadas condiciones, puede resultar afectado gravemente el «mínimo vital» requerido para llevar una «vida normal» (fundamento 14, párrafo 1). La sentencia concluyó esta línea argumentativa señalando que «es indispensable la consideración de la vida en dignidad que, en este caso, se manifiesta como vida saludable» (fundamento 14, párrafo 2).

Por lo demás, la sentencia también establece que el derecho a la salud no solo tiene un aspecto reaccional o de abstención del Estado, sino «una dimensión positiva que lo configura como un típico derecho "prestacional"», esto es, un derecho que exige acciones positivas de las autoridades estatales (fundamento 13). Las circunstancias del caso, empero, determinaban que el Estado adoptara las medidas apropiadas para que cesara la situación de peligro o vulneración de los derechos de los internos cuya salud precaria, debidamente comprobada por los médicos, exigiera su traslado a otro centro penitenciario (fundamento 15, párrafo 2 y fallo).

No está demás indicar que la alta Corte de la constitucionalidad señaló también que el derecho a la visita familiar se veía vulnerado en el caso bajo examen, afectando por ende la finalidad resocializadora de las penas. Al respecto, la sentencia no solo invoca pronunciamientos de órganos de control del DIDH, que sin ser «vinculantes» convergen a «crear convicción» en el Tribunal (fundamento 10); además, afirma que actos como los cuestionados pueden ser lesivos de la dignidad y los derechos fundamentales de los reclusos, si, «al margen de su intencionalidad», pueden incidir o repercutir sobre derechos no restringidos por la orden judicial privativa de la libertad (fundamento 11). Es decir, el Tribunal acoge la figura del impacto adverso de actos en principio neutros o desprovistos de intención dañina.

Un siguiente caso de habeas corpus correctivo en el que se alega que las condiciones carcelarias constituyen «tratos crueles, inhumanos y degradantes», asociándolas en particular con vulneraciones del derecho a la salud, mereció pronunciamiento del Tribunal Constitucional en agosto de 2004. El Tribunal reiteró los criterios interpretativos expuestos en los casos Islas Trinidad, Rodríguez Medrano y Guzmán Reynoso, ya comentados, de suerte que puede decirse que se trata de jurisprudencia constitucional asentada ${ }^{79}$.

\footnotetext{
${ }^{79}$ Resolución del Tribunal Constitucional № 02333-2004-HC, de 12 de agosto de 2004, acápite 2.6. Unos meses antes del fallo emitido en la causa Foronda Crespo y otros, el Tribunal Constitucional dio a conocer una sentencia en la que sistematizaba las diversas modalidades de habeas corpus. En ella, el Tribunal confirma su jurisprudencia en materia de habeas corpus correctivo, pero emplea un lenguaje semejante al de la normativa argentina, pues señala que esta figura se emplea «cuando se producen actos de agravamiento ilegal o arbitrario respecto a las formas o condiciones en que se cumplen las penas privativas de la libertad».
} 


\subsubsection{Las violaciones masivas y sistemáticas de los derechos fundamentales de los reclusos y el estado de cosas inconstitucional}

La situación que padecen las personas privadas de libertad en centros penitenciarios peruanos configura, ciertamente, un cuadro de violaciones masivas y sistemáticas de sus derechos fundamentales. $\mathrm{Y}$ es que los reclusos constituyen un colectivo que se halla en condiciones estructurales de desventaja o especial vulnerabilidad en la sociedad. En tal sentido, el Comité de Derechos Humanos, encargado de supervisar el cumplimiento por los Estados de las obligaciones contraídas en virtud del PIDCP, ha indicado, en la Observación General $\mathrm{N}^{\circ} 21$, que «el párrafo 1 del artículo 10 [del Pacto] impone a los Estados Partes una obligación positiva en favor de las personas especialmente vulnerables por su condición de personas privadas de libertad...»80.

También es posible encontrar en la doctrina nacional de Derecho Penitenciario y en la jurisprudencia del Tribunal Constitucional sobre los derechos fundamentales de los presos manifestaciones de coincidencia con esta caracterización. Así, Diana Milla Vásquez, acuciosa investigadora de la realidad carcelaria peruana, al examinar la temática relativa a los beneficios penitenciarios, ha puesto de relieve cómo la línea jurisprudencial de la alta Corte de la constitucionalidad ha experimentado un punto de inflexión, al considerar el Tribunal que «la igualdad, desde la perspectiva del principio democrático, excluye que ciertas minorías o grupos sociales en desventaja puedan quedarse aislados y $\sin$ voz» ${ }^{81}$. Esta autora plantea que tales conceptos resultan aplicables a la población de internos en centros penales por lo que hace a los beneficios penitenciarios, de los que, por lo tanto, ningún recluso debería verse excluido ${ }^{82}$.

En fin, el propio supremo intérprete de la Constitución ha estatuido jurisprudencialmente que «el Derecho Internacional de los Derechos Humanos, reconociendo que las personas privadas de su libertad constituyen un grupo vulnerable y de especial protección, ha adoptado disposiciones específicas para la tutela de sus derechos, especialmente en el ámbito de las Naciones Unidas (ONU)»83. Y, tras remitirse a los principales cuerpos normativos del Derecho Internacional para la protección de reclusos, tanto en instrumentos formalmente no vinculantes

Agrega, empero, que también es idónea en los casos que «por acción u omisión, importen violación o amenaza del derecho al tra to digno» o cuando «se produzcan tratos inhumanos o degradantes». Y, en fin, sostiene su admisibilidad frente a restricciones arbitrarias de la visita familiar, traslados ilegítimos a otro establecimiento penitenciario y la cohabitación de procesados y condenados en un mismo ambiente. Véase Sentencia del Tribunal Constitucional N 2663-2003-HC, de 23 de marzo de 2004, fundamento 6.c.

${ }^{80}$ Comité de Derechos Humanos (1992), párrafo 3.

${ }^{81}$ Milla (2019), p. 315.

82 Milla (2019), p. 316.

${ }^{83}$ Sentencia del Tribunal Constitucional N01575-2007-PHC, de 20 de marzo de 2009, fundamento 12. 
como en convenios de indudable obligatoriedad jurídica, ha advertido que «el mayor número de violaciones a los derechos humanos que se cometen en el mundo» tiene como víctimas a «personas privadas de libertad, sea esto en establecimientos penitenciarios y en estaciones policiales pero también en hospitales, centros psiquiátricos y zonas de detención» (fundamento 14, párrafo 2).

Ahora bien, el estado de desventaja estructural o dominación en el que se encuentra sumido el colectivo de los reclusos por largo tiempo en el país, con la consiguiente necesidad de adoptar medidas integrales de política pública para atacar sus causas y desmantelarlo, ha sido abordado por el Tribunal Constitucional en tres sentencias en las que hace uso de la técnica de la declaración del estado de cosas inconstitucional. Los dos primeros casos tuvieron como componente esencial que los beneficiarios del habeas corpus padecían desequilibrios psíquicos, mientras que el tercero, muy reciente, aborda frontalmente el problema general del hacinamiento carcelario como subyacente a la violación masiva y sistemática de los derechos fundamentales de los presos.

En la primera causa, resuelta en agosto de 2010, el interno contaba a su favor con una «medida de seguridad» consistente en una orden de internación dispuesta judicialmente, para que fuera trasladado a un hospital en el que pudiera recibir el tratamiento médico especializado que su salud requería. Se hallaba recluido en el penal de Lurigancho, en la ciudad de Lima, en condición de procesado por el cargo de homicidio calificado, pero el tribunal competente en sede jurisdiccional ordinaria lo declaró inimputable por padecer de «síndrome psicótico esquizofrénico paranoide», quedando en consecuencia exento de responsabilidad penal84. La decisión judicial determinaba que debía ser transferido, por un plazo de cuatro años, al Hospital Víctor Larco Herrera, o al Hospital Hermilio Valdizán, o al Instituto Nacional de Salud Mental Hideyo Noguchi (Antecedentes, párrafo 2, y fundamento 20).

Las autoridades penitenciarias intentaron cumplir el mandato judicial en diversas ocasiones y ante los distintos centros médicos indicados, pero en todas las oportunidades la admisión fue rechazada, aduciendo los directores de las entidades de salud sobre todo la falta de espacio para albergar al interno (carencia de camas), como expone detalladamente la sentencia del Tribunal Constitucional (fundamentos 21-23). La alta Corte de la constitucionalidad observó, empero, que «esta situación de hecho no es nueva ni aislada, sino antigua y frecuente», puesto que la

${ }^{84}$ Sentencia del Tribunal Constitucional № 03426-2008-HC, de 26 de agosto de 2010, antecedentes, párrafos 1- 2, fundamentos 1 , 20. 
Defensoría del Pueblo ya la había documentado en un informe del año 2005 (fundamento 24); además, recordó que su propia jurisprudencia había ya establecido el deber del Estado de proveer servicios completos de salud mental, sin que sea posible su supresión por razones de orden presupuestal o administrativo (fundamento 26).

Así, el Tribunal Constitucional transitó desde la atención de un caso individual en el que una persona internada en prisión veía lesionados sus derechos fundamentales a la integridad y a la salud, hacia el problema estructural de todo el colectivo de los reclusos que, padeciendo enfermedades mentales, no recibían el servicio médico especializado que necesitaban. Tal situación, desde luego, implicaba una violación de la dignidad de los presos como titulares de derechos básicos de los que deben gozar en igualdad de condiciones con todas las personas. Por lo demás, la situación de carencias y limitaciones estatales hunde sus raíces en un injusto reparto de recursos y en una desatención inadmisible a un grupo en condiciones de vulnerabilidad, como el de los presos aquejados de disturbios psíquicos.

En correspondencia con estas ideas, el guardián de la Constitución constató la existencia de una «violación masiva y/o generalizada de uno o varios derechos fundamentales (derecho a la salud, integridad personal, etc.) que afectan a un número significativo de personas que adolecen de enfermedad mental», lo que lo llevó a declarar un «estado de cosas inconstitucional» (fundamento 30). Es más, el Tribunal consideró que el problema es de «naturaleza estructural», por lo que su solución únicamente sería posible con «la intervención activa y oportuna no solo de las autoridades emplazadas [las del INPE], sino fundamentalmente, coordinada y/o mancomunada, de los demás sectores o Poderes del Estado (Ministerio de Justicia, Ministerio de Salud, Ministerio de Economía y Finanzas, Congreso de la República, Poder Judicial, etc.)» (fundamento 31).

En definitiva, el Tribunal Constitucional acogió la demanda y ordenó que el señor Marroquín Soto fuera trasladado, «en el día», del penal de Lurigancho al Hospital Larco Herrera, el cual debía admitirlo y para ello «superar cualquier imposibilidad material, a fin de que reciba el tratamiento médico especializado» (punto resolutivo 1). Pero, además de esta decisión, relativa al caso individual, el máximo órgano de la jurisdicción constitucional estableció que configuraba un estado de cosas inconstitucional «la falta de una política de tratamiento y rehabilitación de la salud mental de personas que se encuentran sujetas a medidas de seguridad de internación por padecer de una enfermedad mental» (punto resolutivo 2). De esta manera, el pronunciamiento jurisdiccional proyectaba sus efectos sobre la dimensión colectiva y estructural del problema. 
En consecuencia, la sentencia incluyó órdenes y exhortaciones a diversas entidades públicas para que, de modo concurrente y concertado, contribuyeran a superar la situación lesiva (Ministerio de Economía y Finanzas, Poder Judicial, Congreso de la República, Ministerio de Salud y Ministerio de Justicia).

Es de resaltar que la técnica de la declaración del estado de cosas inconstitucional permite, precisamente, a partir de un litigio concreto, un abordaje integral de un problema estructural que afecta a toda la sociedad. En este caso, se trata de la segregación padecida por el colectivo de los presos, quienes se ven excluidos del igual disfrute de sus derechos básicos. Si bien el Tribunal Constitucional no asume a plenitud en la sentencia el enfoque de la igualdad como no subordinación de grupos sociales en desventaja — deja de lado las dimensiones de reconocimiento y participación-, es claro que su aproximación al caso y al contexto social en el que este se sitúa asume algunos elementos clave de esta concepción, tales como el carácter colectivo del problema, su la índole estructural y la necesidad de acciones positivas del Estado que, movilizando a un conjunto de instituciones públicas, intervengan de manera concertada para adoptar políticas que remuevan las causas sociales de la situación de segregación y opresión que obstaculiza la igualdad real de las personas privadas de libertad.

De cualquier modo, la siguiente sentencia supone un paso adelante en la evolución de la jurisprudencia del Tribunal Constitucional hacia una visión más comprehensiva y justa de la igualdad respecto a la población carcelaria en el Perú. En efecto, en una decisión bastante más reciente, emitida en junio del año 2019, el Tribunal evaluó el habeas corpus correctivo presentado a favor de un recluso que venía purgando condena en el penal limeño de Lurigancho por la comisión de homicidio ${ }^{85}$. Si bien hubo discrepancias entre distintos médicos que examinaron al interno, la controversia giraba precisamente en torno a si padecía una grave perturbación psíquica («esquizofrenia psicosis paranoide») que justificara su traslado a un establecimiento psiquiátrico donde pudiera recibir atención especializada (Antecedentes, párrafos 2 y 12-16).

Es de lamentar que la excesiva demora en la resolución del proceso determinara la sustracción de la materia, ya que antes de que el Tribunal Constitucional expidiera el fallo, la condena fue cumplida por el beneficiario del habeas corpus: por muy impresionante que pueda ser, transcurrieron más de seis años y medio desde la presentación de la demanda hasta la

${ }^{85}$ Sentencia del Tribunal Constitucional № 04007-2015-HC, de 27 de junio de 2019, antecedentes, párrafo 2. 
sentencia del Tribunal Constitucional (fundamentos 1 y 2), en un proceso diseñado para ser resuelto en primera instancia »de inmediato» $y$, respecto de ciertas modalidades especiales, «en el término de un día natural, bajo responsabilidad» (artículos 30 y 31 del Código Procesal Constitucional). Como quiera que fuere, la alta Corte de la constitucionalidad tuvo en cuenta, de un lado, «la magnitud del agravio producido», y, de otro lado, que la situación resultaba «representativa de todo un grupo de personas que, estando internadas en alguno de los establecimientos penitenciarios del país, tienen problemas de salud mental» (fundamento 2). Por estas razones, en aplicación del artículo 1, párrafo 2 del Código Procesal Constitucional, el Tribunal decidió pronunciarse sobre la controversia. Desde luego, el propósito era establecer lineamientos interpretativos que pudieran orientar decisiones futuras en casos similares.

Esta vez, el guardián de la Carta Fundamental, además de reiterar sus criterios ya bien establecidos acerca de las características del habeas corpus correctivo (fundamentos 4-5), hizo una exposición amplia y detallada del derecho a la salud y, en particular, del derecho a la salud mental (fundamentos 6-21). Singularmente prolijo fue también en lo atinente a la salud mental de las personas privadas de libertad en centros penitenciarios, invocando jurisprudencia de la Corte IDH para aludir al vínculo entre el cuidado de la salud de quienes padecen una discapacidad mental y su «derecho a la vida digna» (caso Ximenes Lopes vs. Brasil), así como citando un pronunciamiento de la CIDH en el que se desestima la alegación del Estado de hallarse ante «obstáculos estructurales que le impiden proveer tratamiento médico y psiquiátrico a las personas bajo custodia» (caso Víctor Rosario Congo vs. Ecuador) (fundamentos 23-24).

Particular relevancia adquieren ciertas manifestaciones del Tribunal Constitucional que sitúan su decisión en el marco conceptual de la igualdad como no dominación o no sometimiento. Y es que el Tribunal, al insistir en que el caso bajo análisis es expresivo de «un problema que aqueja a un considerable número de personas», dice, significativamente, que los reclusos constituyen «una población vulnerable de forma múltiple» (fundamento 22). Asimismo, el máximo órgano jurisdiccional, recalcando elementos vinculados al derecho a la igualdad de colectivos segregados y oprimidos, asevera que el derecho a la salud mental es un derecho fundamental y de eficacia vinculante «para todas las personas», de suerte que «no puede excluirse de su protección a las personas privadas de libertad en centros penitenciarios», ya que sobre ellas «solo operan las restricciones de derechos que se hayan dispuesto en la respectiva resolución judicial o las previstas en la respectiva ley de ejecución penal» (fundamento 28). 
En esta línea de razonamiento, que adhiere a la noción de igualdad como no subordinación, se inserta también el voto concurrente del magistrado Espinoza-Saldaña Barrera. En efecto, el fundamento de voto de este juez, que respalda la decisión adoptada por la mayoría del colegiado, encuentra justificación a la tutela conferida por el Tribunal Constitucional «no solo desde una perspectiva individual, sino también coadyuvando a que sean desmontadas estructuras sociales injustas, muchas veces avaladas o consentidas por el Estado (por acción o por omisión)» (fundamento 11).

Algo semejante puede decirse del fundamento de voto emitido por el magistrado Ferrero Costa. Este, efectivamente, apunta que la carencia de un protocolo para la detección y tratamiento de internos con enfermedades mentales «debe ser revertida en un breve plazo, toda vez que es una tarea conjunta de todos órganos del Estado promover la inclusión social y fiscalizar su cumplimiento para así remover las barreras, y propiciar una reinserción de los presos a la sociedad conforme al inciso 22 del artículo 139 de la Constitución» (fundamento 4).

A mayor abundamiento, el supremo intérprete de la Constitución recordará su propia jurisprudencia, para subrayar que los reclusos «tienen un derecho constitucional a la salud al igual que cualquier persona», pero con la peculiaridad de que en su caso es el Estado quien asume la responsabilidad de garantizar la salud de los internos (fundamento 30).

En definitiva, el Tribunal Constitucional, tras consultar estadísticas oficiales acerca del problema de desatención de la salud mental de la población carcelaria (fundamentos 35-41), así como luego de establecer las «características imprescindibles» que deben cumplir los servicios de salud mental — disponibilidad, accesibilidad, aceptabilidad y calidad — (fundamentos 43-60), hace notar que los establecimientos penitenciarios tienen un subregistro de personas con perturbaciones psíquicas que no han sido diagnosticadas ni reciben tratamiento especializado (fundamento 72).

Sobre la base de todos estos elementos, el supremo intérprete de la Constitución procura remediar la situación que encuentra en el caso, la cual considera que responde a una violación «generalizada y sistemática» del derecho a la salud mental de las personas privadas de libertad en centros penitenciarios (fundamentos 73-74). Adicionalmente, el Tribunal juzga que la situación del recluso MHFC es «idéntica» a la de muchos internos que, a lo largo de todo el país, pese a sufrir desequilibrios psíquicos, carecen de atención médica (fundamento 77). La técnica a emplear ha de ser entonces, como ya se ha adelantado, la declaración de un «estado de cosas 
inconstitucional», el cual parte de reconocer que el anterior, que fue estatuido en el caso Marroquín Soto, tras ocho años de la expedición de la sentencia, no ha producido los resultados esperados, en tanto no se cuenta aún con una política nacional de salud mental que pudiera servir también en el caso ahora bajo análisis (fundamento 80).

El fallo apunta, por lo tanto, a obtener una solución integral, para lo cual prevé medidas de reparación «transformadoras» cuya realización exige una compleja operación concurrente y coordinada de diversas entidades estatales para el diseño e implementación de políticas públicas, en un período de tiempo de cierta duración. Así, la sentencia no solo estima la demanda por considerar que se ha vulnerado la salud del beneficiario del habeas corpus, ordenando su evaluación, diagnóstico y tratamiento por el Ministerio de Salud (punto resolutivo 1). Además de ello, irradiando más allá del caso singular y extendiendo sus efectos a nivel nacional, la sentencia declara «un estado de cosas inconstitucional con respecto a la situación de salud mental de las personas que se encuentran internadas en los establecimientos penitenciarios del país» (punto resolutivo 2). En consecuencia, el fallo contiene órdenes a diversas entidades públicas para elaborar e implementar un plan de acción que permita corregir la situación.

La tercera decisión es muy reciente, pues ha sido emitida en el novísimo contexto de la pandemia desatada por el coronavirus y su negativo impacto en la población carcelaria del país. También se trata de un proceso de «habeas corpus correctivo» muy prolongado, en vista de que transcurrieron nada menos que cinco años y 8 meses desde la interposición de la demanda hasta que el Tribunal resuelve la controversia ${ }^{86}$.

En cuanto a lo que interesa a la presente investigación, el reclamante alega, de un lado, que no recibe el tratamiento médico que requiere para las enfermedades de gripe y bronquitis que padece, las cuales - asevera - se han vuelto crónicas justamente por no haber sido atendidas de manera oportuna; de otro lado, afirma que lleva un largo tiempo (dos años y medio) durmiendo en el suelo del penal, lo que también vulnera sus derechos a la integridad personal y a la salud (Antecedentes, párrafo 1 y fundamento 1). A su turno, el director del establecimiento penitenciario Pocollay, del departamento de Tacna, donde se produjeron los hechos del caso, sostuvo que la situación de «hacinamiento» existente en la prisión había llevado a que esta fuera declarada «en emergencia por falta de infraestructura», y que de allí derivaba la imposibilidad de que los reclusos contaran con «camas individuales» (fundamento 3 ).

${ }^{86}$ Sentencia del Tribunal Constitucional N 05436-2014-PHC, de 26 de mayo de 2020, antecedentes, párrafo 1. 
Dadas las características del caso, el guardián de la Carta Fundamental decidió evaluar el desafío al Estado constitucional y democrático de Derecho que plantea «la problemática del hacinamiento» en las cárceles peruanas, a la luz de las normas del Derecho Constitucional y de los estándares consagrados en los instrumentos del Derecho Internacional de los Derechos Humanos (fundamento 4). El Tribunal expone de manera pormenorizada el contenido y la evolución de su jurisprudencia en materia de habeas corpus correctivo - siempre de acuerdo con los principios de legitimidad, legalidad, razonabilidad y proporcionalidad-, incluyendo sus dos pronunciamientos declarativos de sendos estados de cosas inconstitucionales por los problemas de salud mental de internos, ya analizados aquí (fundamentos 5-23).

La revisión que el supremo intérprete de la Constitución hace de la problemática del hacinamiento carcelario es exhaustiva y minuciosa, en primer lugar, al consultar el amplio desarrollo de estándares internacionales normativos y jurisprudenciales que están vigentes y son aplicables en el Perú, entre los que se encuentran informes de la CIDH y del Comité de Derechos Humanos, sentencias de la Corte IDH (caso García Asto y Ramírez Rojas vs. Perú, caso López Álvarez vs. Honduras, caso Retén de Catia vs. Venezuela) y las Reglas Mandela (fundamentos 28-51). En segundo lugar, el Tribunal es acucioso al examinar la situación fáctica que padecen los reclusos, para lo que consulta diversos informes de la Defensoría del Pueblo, pero también las estadísticas oficiales del INPE (fundamentos 58-82).

Las normas del Derecho Constitucional y los estándares del DIDH sirven a la alta Corte de la constitucionalidad para fulminar como inadmisible el hacinamiento, por atentar contra la dignidad de los reclusos y sus derechos básicos. La constatación de la lacerante realidad de hecho, a su vez, le vale para dimensionar el enorme reto que enfrenta la democracia constitucional y para ponderar la naturaleza compleja, multicausal, estructural e histórica del problema. De allí la declaración del estado de cosas inconstitucional y la necesidad de prever un conjunto de intervenciones a ejecutar como medidas de reparación transformadoras a lo largo de un período de tiempo más bien dilatado, incluyendo una serie de acciones urgentes en particular en el contexto de la pandemia del coronavirus (fundamentos 83-107). Es importante también anotar que el Tribunal es consciente de que la solución a las violaciones masivas de los derechos fundamentales de los internos no está solo en evitar el hacinamiento, sino en resolver el problema del incremento desmedido de las penas y de la misma persecución penal (fundamentos 26-27). 
Ahora bien, por lo que atañe a la perspectiva de la igualdad como no dominación o no sometimiento, aplicable al colectivo de reclusos, el Tribunal hace igualmente varias referencias valiosas. En tal sentido, cita la Observación General N² 21 del Comité de Derechos Humanos, ya mencionada en este artículo, que considera a las personas privadas de libertad como «especialmente vulnerables», añadiendo que este documento internacional también estipula el deber de garantía de la dignidad de los presos «en las mismas condiciones aplicables a las personas libres» (fundamento 32).

Asimismo, al exigir el pleno respeto del principio de trato digno a los presos en armonía con la normativa constitucional y del DIDH, el Tribunal Constitucional advierte que las medidas a adoptar serán una contribución importante para hacer frente y reparar «la situación estructural de vulneración de derechos fundamentales por la que atraviesan los reclusos desde hace décadas en el Perú» (fundamento 93). A ello se agrega la calificación del hacinamiento penitenciario como una «violación sistemática» de los derechos fundamentales de los internos (fundamento 107.c) y la todavía más clara alusión a que medidas de orden general, tales como el eventual cierre de establecimientos carcelarios hacinados, encuentran justificación indudable «cuando se trata de graves, permanentes, históricas y sistemáticas violaciones a los derechos fundamentales de todo un colectivo de personas privadas de libertad» (fundamento 107.d, segundo párrafo).

Estas afirmaciones y referencias ubican a esta sentencia del Tribunal Constitucional, lo mismo que a las dos anteriores sobre estado de cosas inconstitucional, en el marco conceptual de la igualdad como no dominación o no subordinación. Y es que el supremo intérprete de la Constitución aborda las cuestiones relativas al hacinamiento y a la conculcación de los derechos a la vida, integridad, salud y trato digno al interior de las cárceles, considerando a la población de reclusos como un grupo vulnerable, que se halla en una situación que imposibilita a sus miembros ejercer en igualdad sus derechos fundamentales, lo que se debe a una situación estructural. En efecto, el Tribunal estima que la violación de los derechos básicos de los internos es de naturaleza «sistemática» y además de larga duración — permanente, histórica一, afectando en su conjunto al colectivo de los presos.

Pese a este considerable avance en la elaboración del discurso jurídico constitucional de tutela de los derechos fundamentales de las personas privadas de libertad, es claro también que la sentencia se resiente aún de ciertas insuficiencias y omisiones. Así, debe observarse que esta decisión, lo mismo que las dos anteriores, deja de lado en gran medida la dimensión del 
reconocimiento y de la participación, que forman parte del enfoque integral que procura la remoción de las causas estructurales que mantienen a determinados grupos desaventajados en condiciones de marginación y opresión, según ha sido expuesto aquí (véase el acápite II.2, supra).

El colectivo de las personas privadas de libertad, precisamente, se halla en una situación de inferioridad muy grande y es objeto de visiones prejuiciosas y de representaciones a menudo denigrantes y segregacionistas. La escasez de recursos asignados por el Estado peruano a las prisiones, su desatención de las necesidades básicas de los reclusos y la configuración de un estado de cosas violatorio de los derechos humanos, el cual se mantiene de hecho desde la fundación misma del sistema penitenciario ${ }^{87}$, parece responder al predominio en la sociedad de ideas y actitudes punitivas y de populismo penal que tienden a despreciar y a estigmatizar a los «delincuentes» como personas ajenas al pacto político-social e incapaces de reintegrarse a la comunidad tras un paso por la cárcel que los marcará para siempre88.

Por solo mencionar un punto significativo, a manera de ilustración, el Tribunal Constitucional no se preocupa de reconocer a las organizaciones de los reclusos y a sus dirigentes o delegados ${ }^{89}$. Ello no solo contribuiría a visibilizar sus necesidades y reclamos, sino además y quizá principalmente, a dar voz propia al colectivo de personas privadas de libertad. Permanece muy extendida, a nivel de las instituciones y la cultura de todo el país, la actitud y la práctica de excluir a los presos de la toma de decisiones que les atañen y en las que podrían intervenir legítimamente. Hace falta, empero, que se les reconozca como interlocutores válidos y como agentes capaces de moldear sus destinos, asumiendo, desde su condición de reclusos, tareas y compromisos importantes con responsabilidad. En esa línea de reflexión, es igualmente destacable que la Comisión de Alto Nivel para la Reforma Política, nombrada por el Poder Ejecutivo, haya incluido entre sus propuestas de rediseño del sistema político y de las instituciones electorales algo tan sencillo y primordial como abrir mesas de sufragio en los centros penitenciarios ${ }^{90}$, pues debe recordarse que los internos procesados no tienen formalmente limitados sus derechos de participación política, a diferencia de los condenados (artículo 33 de la Constitución), pero sí se ven impedidos de ejercerlos de hecho, con todo lo grave que es tal exclusión.

\footnotetext{
${ }^{87}$ Aguirre (2011), pp. 105, 107-111.

${ }^{88}$ CEAS (2015), pp. 9-11, 19, 22, 31, 38; Consejo Nacional de Política Criminal (2016), pp. 38-43; Defensoría del Pueblo (2018), pp. 34-35.

${ }^{89}$ Sobre la existencia y organización del sistema de delegados en los penales, véase Pérez Guadalupe (1994), pp. 54-62; véanse también Defensoría del Pueblo (2006), p. 11; Defensoría del Pueblo (2011), p. 223.

${ }^{90}$ CANRP (2019), p. 56.
} 
Como quiera que fuere, el Tribunal Constitucional busca trascender el caso individual y atacar el problema estructural de la cárcel en el Perú, con su nocivo efecto de violaciones masivas y sistemáticas de los derechos fundamentales de los presos. En consecuencia, en un fallo de enorme significación, declara la existencia de «un estado de cosas inconstitucional respecto del permanente y crítico hacinamiento de los establecimientos penitenciarios y las severas deficiencias en la capacidad de albergue, calidad de su infraestructura e instalaciones sanitarias, de salud, de seguridad, entre otros servicios básicos, a nivel nacional» (punto resolutivo 3).

\section{Conclusión}

Con la reciente expedición de la sentencia del caso CCB ${ }^{91}$ (STC 05436-2014-PHC/TC), el Tribunal Constitucional parece haber llegado a la culminación de una etapa en su evolución jurisprudencial en materia de tutela de derechos fundamentales de personas privadas de libertad. Y es que, con esta decisión, por primera vez la alta Corte de la constitucionalidad declara que el hacinamiento subyace como factor estructural de las violaciones masivas y sistemáticas de los derechos fundamentales de quienes sufren prisión en el país, sea como procesados o sea como condenados por la comisión de delitos, por lo que existe un «estado de cosas inconstitucional».

En términos que son a la vez procesales y sustantivos, dicha evolución ha llevado al Tribunal desde la creación del «habeas corpus correctivo», luego plasmado normativamente en el Código Procesal Constitucional (artículo 25.17), al empleo de la técnica de la declaración del «estado de cosas inconstitucional».

Es digno de ser resaltado que el Tribunal estima en su nueva jurisprudencia, con cada vez mayor claridad, que la situación que padecen los reclusos es de carácter estructural en la sociedad peruana, tiene raíces históricas, tiende a perpetuarse y afecta a un colectivo de personas que se encuentra en situación de desventaja o de especial vulnerabilidad. Las sentencias más recientes revelan que el máximo órgano jurisdiccional ha acogido parcialmente la concepción de la igualdad como no dominación o no sometimiento, la cual permite trascender los casos individuales y la mera apreciación de tratos diferenciados arbitrarios o carentes de razonabilidad, para procurar más bien la remoción de las barreras que impiden al colectivo de los presos el goce y ejercicio igualitario de sus derechos fundamentales, estipulados en las

${ }^{91}$ Sentencia del Tribunal Constitucional Nº5436-2014-PHC, de 26 de mayo de 2020. 
normas del Derecho Constitucional y en los instrumentos del Derecho Internacional de los Derechos Humanos.

Quedan, no obstante, algunas tareas pendientes, en particular, la introducción de la dimensión de reconocimiento y participación entre las medidas que deben establecerse para un mejor respeto y garantía de los derechos fundamentales de los reclusos. Ciertamente, a ello puede contribuir de manera importante la jurisprudencia del Tribunal Constitucional mediante acciones transformadoras, las cuales habrán de adaptarse a las diferencias internas del universo de personas privadas de libertad.

\section{Bibliografía citada}

Aguirre, Carlos (2011): "La penitenciaría de Lima y la modernización de la justicia penal en el Perú del siglo XIX", en Aguirre, Carlos (Ed.), Dénle duro que no siente: poder y transgresión en el Perú republicano (Lima, AFINED), pp. 93-113.

Alexy, Robert (1997): Teoría de los derechos fundamentales (Madrid, Centro de Estudios Constitucionales).

Alzamora Silva, Lizardo (2004): Estudios Constitucionales, 2a ed. (Lima, Editora Jurídica Grijley).

Añón Roig, María José (2013): "Principio antidiscriminatorio y determinación de la desventaja", en Isonomía - Revista de Teoría y Filosofía Del Derecho (№339), pp. 127-157.

Ariza, Libardo José (2011): "Reformando el infierno: los tribunales y la transformación del campo penitenciario en América Latina", en Ariza, Libardo e Iturralde, Manuel (eds.), Los muros de la infamia: prisiones en Colombia y en América Latina (Bogotá: Universidad de los Andes), pp. 18-108.

Basadre, Jorge (1983): Historia de la República del Perú, 7ae ed. (Lima, Editorial Universitaria).

Bernal Pulido, Carlos (2005): "El juicio de igualdad en la jurisprudencia de la Corte Constitucional", en Bernal Pulido, Carlos (ed.), El Derecho de los derechos (Bogotá: Universidad Externado de Colombia), pp. 255-283. 
Bustamante Peña, Gabriel (2011): Estado de cosas inconstitucional y politicas públicas (Bogotá, Pontificia Universidad Javeriana).

Castro Morales, Álvaro (2018): "Estándares de la Corte Interamericana de Derechos Humanos en materia de imputados y condenados privados de libertad", en Anuario de Derechos Humanos ( $\left.\mathrm{N}^{\circ} 14\right)$, pp. 35-54.

Clérico, Laura y Aldao, Martín (2011): “Nuevas miradas de la igualdad en la jurisprudencia de la Corte Interamericana de Derechos Humanos: la igualdad como redistribución y como reconocimiento", en Lecciones y Ensayos ( ${ }^{\circ}$ 89), pp. 141-179.

Clérico, Laura, Ronconi, Liliana y Aldao, Martín (2013): "Hacia la reconstrucción de las tendencias jurisprudenciales en América Latina y el Caribe en materia de igualdad: sobre la no-discriminación, la no-dominación y la redistribución y el reconocimiento", en Direito GV Law Review (Vol. 9, № 1), pp. 115-170.

Comisión de Alto Nivel para la Reforma Política (CANRP) (2019): Hacia la democracia del bicentenario (Lima, Konrad Adenauer Stiftung).

Comisión Episcopal de Acción Social (CEAS) (2015): La cárcel en el Perú: conocer la realidad para transformarla (Lima, CEAS).

Comisión Interamericana de Derechos Humanos (CIDH) (2003): Informe Especial sobre la Situación de los Derechos Humanos en la Cárcel de Challapalca, Departamento de Tacna, República del Perú (Washington D.C., CIDH).

(CIDH) (2017a): Guía práctica para reducir la prisión preventiva (Washington D.C., CIDH).

(CIDH) (2017b): Informe sobre medidas dirigidas a reducir el uso de la prisión preventiva en las Américas. (Washington D.C., CIDH).

Comisión de la Verdad y Reconciliación (2003): Informe Final (Lima, CVR).

Comité de Derechos Humanos (Comité DDHH) (1992): Observación General N²1, "Trato humano de las personas privadas de libertad (artículo 10)" (Ginebra, Comité DDHH). 
Consejo Nacional de Política Criminal (2016): Política Nacional Penitenciaria y Plan Nacional de la Política Penitenciaria 2016 - 2020 (Lima, Ministerio de Justicia y Derechos Humanos).

Corte Interamericana de Derechos Humanos (Corte IDH) (2003). "Condición Jurídica y Derechos de los Migrantes Indocumentados". Opinión Consultiva OC-18/03 de 17 de septiembre de 2003. Serie A № 18”. [Disponible en: https://bit.ly/3g3e1df] [Fecha de consulta: 6 de febrero de 2020].

Courtis, Christian (2010): "Dimensiones conceptuales de la protección legal contra la discrminación", en Revista Derecho del Estado (№ 24), pp. 105-141.

Crenshaw, Kimberle (1991): "Mapping the Margins: Intersectionality, Identity Politics, and Violence Against Women of Color", en Stanford Law Review (Vol. 43, № 6), pp. 1241-1299.

Defensoría del Pueblo (2003): Informe sobre el Establecimiento Penitenciario de Régimen Cerrado Especial de Challapalca (Lima, Defensoría del Pueblo).

(2006): Supervisión del Sistema Penitenciario 2006 (Lima, Defensoría del Pueblo).

(2007): La discriminación en el Perú: problemática, normatividad y tareas pendientes (Lima, Defensoría del Pueblo).

(2011): El sistema penitenciario: componente clave de la seguridad y la política criminal. Problemas, retos y perspectivas (Lima, Defensoría del Pueblo).

(2018): Retos del Sistema Penitenciario Peruano: Un diagnóstico de la realidad carcelaria de las mujeres y varones (Resumen Ejecutivo) (Lima, Defensoría del Pueblo).

Díaz de Valdés, José Manuel (2015): "La igualdad constitucional: múltiple y compleja", en Revista Chilena de Derecho (Vol. 42, N 1), pp. 153-187.

Dworkin, Ronald (2012a): "Liberalismo", en Una cuestión de principios (Buenos Aires: Siglo Veintiuno Editores), pp. 231-258.

(2012b): Los derechos en serio (Barcelona: Ariel).

Eguiguren, Francisco (2002): "Principio de igualdad y derecho a la no discriminación", en Estudios Constitucionales (Lima, ARA Editores), pp. 93-118. 
Ferrajoli, Luigi (2016): "Jurisdicción y ejecución penal. La cárcel: una contradicción institucional", en Revista Crítica Penal y Poder (N 11), pp. 1-10. (2019): Manifiesto por la igualdad (Madrid, Editorial Trotta).

Fiss, Owen (1999): "Grupos y la cláusula de la igual protección", en Gargarella, Roberto (ed.), Derecho y grupos desaventajados (Barcelona, Editorial Gedisa), pp. 137-167. (2007): El Derecho como razón pública (Madrid, Marcial Pons).

Foucault, Michel (2019): Vigilar y castigar: nacimiento de la prisión (Buenos Aires, Siglo Veintiuno Editores).

Fraser, Nancy (1996): "Redistribución y Reconocimiento: hacia una visión integrada de justicia del género", en Revista Internacional de Filosofía Política (№ 8), pp. 18-40.

(2010a): "Injustice at intersecting scales: On "social exclusion" and the "global poor"", en European Journal of Social Theory (Vol. 13, № 3), pp. 363-371.

(2010b): Scales of Justice: Reimagining Political Space in a Globalizing World (Nueva York, Columbia University Press).

Gargarella, Roberto (2008): "Mano dura contra el castigo (I). Igualdad y comunidad", en Gargarella, Roberto (ed.), De la injusticia penal a la justicia social (Bogotá, Siglo del Hombre Editores - Universidad de los Andes), pp. 25-52.

Giménez Glück, David (2004): Juicio de igualdad y Tribunal Constitucional (Barcelona, Editorial Bosch).

Hakansson Nieto, Carlos (2009): Curso de Derecho Constitucional. Palestra Editores.

Huerta Guerrero, Luis Alberto (2005): "El derecho a la igualdad", en Pensamiento Constitucional ( $\left.\mathrm{N}^{\circ} 11\right)$, pp. 307-334.

(2008): "Tipos de habeas corpus en el ordenamiento jurídico peruano", en Castillo Córdova, Luis (ed.), En defensa de la libertad personal: estudios sobre el habeas corpus (Lima, Palestra Editores), pp. 89-105. 
Landa, César (2006): "Implementación de las decisiones del sistema interamericano de derechos humanos en el ordenamiento constitucional peruano", en Landa, César (ed.), Constitución y fuentes del Derecho (Lima, Palestra Editores), pp. 117-132.

(2018): Los derechos fundamentales (Lima, Pontificia Universidad Católica del Perú).

Milla Vásquez, Diana (2019): Beneficios penitenciarios y otras instituciones penitenciarias (Lima, Instituto Pacífico).

Naciones Unidas (2015): Reglas Mínimas de las Naciones Unidas para el Tratamiento de los Reclusos (Reglas Nelson Mandela). Resolución aprobada por la Asamblea General el 17 de diciembre de 2015 (Ginebra, Naciones Unidas).

Nash, Claudio (2013): "Estudio introductorio: derechos humanos y mujeres, teoría y práctica", en Lacrampette, Nicole (ed.), Derechos humanos y mujeres: teoría y práctica (Santiago de Chile, Centro de Derechos Humanos - Universidad de Chile), pp. 13-29.

Nash, Claudio y David, Valeska (2010): "Igualdad y no discriminación en el sistema interamericano de derechos humanos", en Nash, Claudio y Mujica, Ignacio (eds.), Derechos humanos y juicio justo (Lima, Red interamericana de formación en gobernabilidad y derechos humanos, Colegio de las Américas y Organización Interamericana), pp. 159-186.

Nogueira Alcalá, Humberto (2006): "El derecho a la igualdad ante la ley, no discriminación y acciones positivas", en Revista de Derecho de la Universidad Católica del Norte (Vol. 13, N 2), pp. 61-100.

Pareja Paz-Soldán, José (1984): Derecho Constitucional Peruano y la Constitución de 1979, 3ª̣ ed. (Lima, Ediciones Justo Valenzuela).

Pérez Guadalupe, José Luis (1994): Faites y atorrantes: una etnografía del penal de Lurigancho (Lima, Centro de Investigaciones Teológicas).

Porras Barrenechea, Raúl (1974): Los ideólogos de la emancipación (Lima, Editorial Milla Batres). 
Ramírez Huaroto, Beatriz (2013): El “estado de cosas inconstitucional” y sus posibilidades como herramienta para el litigio estratégico de Derecho Público. Una mirada a la jurisprudencia colombiana y peruana (Lima, Pontificia Universidad Católica del Perú).

Ramos Núñez, Carlos (ed.) (2017): Las Constituciones del Perú (Lima, Centro de Estudios Constitucionales del Tribunal Constitucional - Ministerio de Justicia y Derechos Humanos).

Rey Martínez, Fernando (2008): "La discriminación múltiple, una realidad antigua, un concepto nuevo", en Revista Española de Derecho Constitucional (Nº 84), pp. 251-283.

Rodríguez Gamero, Marco Alonso (2020): "Nuevas perspectivas conceptuales en la afirmación del derecho a la igualdad de las personas con discapacidad mental: una evaluación crítica de la jurisprudencia del Tribunal Constitucional peruano", en Estudios Constitucionales (Vol. $\left.18, \mathrm{~N}^{\circ} 1\right)$, pp. $145-211$.

Ronconi, Liliana (2019): "Repensando el principio de igualdad: alcances de la igualdad real", en Isonomía ( $\left.\mathrm{N}^{\circ} 49\right)$, pp. 103-140.

Saba, Roberto (2018): Más allá de la igualdad formal ante la ley. ¿Qué les debe el Estado a los grupos desaventajados? (Buenos Aires, Siglo Veintiuno Editores).

Sagüés, Néstor Pedro (1998): Derecho Procesal Constitucional (Tomo 4): habeas corpus (Buenos Aires, Editorial Astrea).

Salomé, Liliana (2015): La “discriminación múltiple” como concepto jurídico para el análisis de situaciones de discriminación (Lima, Pontificia Universidad Católica del Perú).

(2017): "La discriminación y algunos de sus calificativos: directa, indirecta, por indiferenciación, interseccional (o múltiple) y estructural", en Pensamiento Constitucional ( $\left.\mathrm{N}^{\circ} 22\right)$, pp. 255-290.

Sánchez Benites, Rosa Isabel (2020): "Los derechos fundamentales frente a las cárceles hacinadas en tiempos de la pandemia de covid-19", en Landa, C. (ed.), Constitución y emergencia sanitaria (Lima, Palestra Editores), pp. 143-160. 
Torres Zúñiga, Natalia (2013): "Control de convencionalidad y protección multinivel de los derechos humanos en el Sistema Interamericano de Derechos Humanos", en Derecho PUCP ( $\left.\mathrm{N}^{\circ} 70\right)$, pp. 347-369.

Villarán, Manuel Vicente (1962): "La Constitución de 1823", en Páginas Escogidas (Lima, Talleres Gráficos P.L. Villanueva), pp. 33-44.

Young, Iris Marion (1990): Justice and the politics of difference (Princeton: Princeton University Press).

Zapata, Antonio (2017): La guerra senderista: hablan los enemigos (Lima, Taurus).

\section{Normas jurídicas citadas}

Constitución de Colombia, 1991.

Constitución de Italia, 1947.

Constitución Política del Perú, 1993.

Decreto Legislativo 654, que promulga el Código de Ejecución Penal. El Peruano, 2 de agosto de 1991.

Decreto Ley 25475, mediante el cual establecen la penalidad para los delitos de terrorismo y los procedimientos para la investigación, la instrucción y el juicio. El Peruano, 5 de mayo de 1992.

Ley 28237, que promulga el Código Procesal Constitucional. El Peruano, 31 de mayo de 2004.

\section{Jurisprudencia citada}

Corte Interamericana de Derechos Humanos: Caso García Asto y Ramírez Rojas vs. Perú, Serie C $\mathrm{N}^{\circ} 137$, de 25 de noviembre de 2005.

Corte Interamericana de Derechos Humanos: Caso del Penal Miguel Castro Castro vs. Perú, Serie C N 160 , de 25 de noviembre de 2006. 
Corte Interamericana de Derechos Humanos: Caso González y Otras ("Campo Algodonero") vs. México, Serie C N²05, de 16 de noviembre de 2009.

Corte Interamericana de Derechos Humanos: Caso Atala Riffo y niñas vs. Chile, Serie C $\mathrm{N}^{\circ} 254$, de 24 de febrero de 2012.

Corte Interamericana de Derechos Humanos: Caso Chinchilla Sandoval y otros vs. Guatemala, Serie $\mathrm{C} \mathrm{N}^{\circ} 312$, de 29 de febrero de 2016.

Tribunal Constitucional del Perú: Caso Guzmán Reynoso y otra (proceso de habeas corpus, resolución), Expediente 0590-2001-HC, de 22 de junio de 2001.

Tribunal Constitucional del Perú: Caso Rodríguez Medrano (proceso de habeas corpus), Expediente 0726-2002-HC, de 21 de junio de 2002.

Tribunal Constitucional del Perú: Caso Islas Trinidad y otros (proceso de habeas corpus), Expediente 1429-2002-HC, de 19 de noviembre de 2002.

Tribunal Constitucional del Perú: Caso de la legislación antiterrorista (acción de inconstitucionalidad), Expediente 010-2002-AI, de 3 de enero de 2003.

Tribunal Constitucional del Perú: Caso Aponte Chuquihuanca (proceso de habeas corpus), Expediente 2663-2003-HC, de 23 de marzo de 2004.

Tribunal Constitucional del Perú: Caso Foronda Crespo y otras (proceso de habeas corpus, resolución), Expediente 02333-2004-HC, de 12 de agosto de 2004.

Tribunal Constitucional del Perú: Caso Castillo Chirinos (proceso de amparo), Expediente 27302006-PA, de 21 de julio de 2006.

Tribunal Constitucional del Perú: Caso de los Decretos Legislativos 921-927 (proceso de inconstitucionalidad), Expediente 003-2005-PI, de 9 de agosto de 2006.

Tribunal Constitucional del Perú: Caso Marroquín Soto (proceso de habeas corpus), Expediente 03426-2008-HC, de 26 de agosto de 2010.

Tribunal Constitucional del Perú: Caso Cieza Fernández (proceso de amparo), Expediente 00853-2015-PA, de 14 de marzo de 2017. 
Tribunal Constitucional del Perú: Caso Cáceres Ramos (proceso de amparo), Expediente 012722017-PA, de 5 de marzo de 2019.

Tribunal Constitucional del Perú: Caso MHFC (proceso de habeas corpus), Expediente 040072015-HC, de 27 de junio de 2019.

Tribunal Constitucional del Perú: Caso CCB (proceso de habeas corpus), Expediente 054362014-PHC, de 26 de mayo de 2020. 